\title{
Energy materials
}

\section{Carbon nitride materials: impact of synthetic method on photocatalysis and immobilization for photocatalytic pollutant degradation}

\author{
Isabel Köwitsch ${ }^{1,2}$ and Michael Mehring ${ }^{1,2, *}$ (1) \\ ${ }^{1}$ Fakultät für Naturwissenschaften, Institut für Chemie, Technische Universität Chemnitz, Professur Koordinationschemie, Straße \\ der Nationen 62, 09107 Chemnitz, Germany \\ ${ }^{2}$ Center for Materials, Architectures and Integration of Nanomembranes (MAIN), Rosenbergstraße 6, 09126 Chemnitz, Germany
}

Received: 3 April 2021

Accepted: 31 July 2021

Published online:

16 August 2021

(C) The Author(s) 2021

\begin{abstract}
Different synthesis routes for carbon nitride materials $(\mathrm{CN})$ and the resulting products were compared to study the photocatalytic activity (pollutant degradation) in dependence on structure and properties. The $\mathrm{CN}$ materials were synthesized by thermal decomposition of dicyandiamide in air and under argon as well as in sealed ampoules with or without the use of a salt melt. The asprepared materials were characterized by IR spectroscopy, nitrogen adsorption measurement, solid-state NMR spectroscopy, diffuse reflectance UV-Vis spectroscopy, elemental analysis and powder X-ray diffraction (PXRD). The surface polarity of the $\mathrm{CN}$ materials was estimated by adsorption of the dicyanobis(1,10-phenanthroline)-iron(II) complex, which allows an evaluation of the degree of condensation. The $\mathrm{CN}$ materials were tested with regard to the photocatalytic degradation of rhodamine $\mathrm{B}(\mathrm{RhB})$. It is shown that the photocatalytic activity increases with higher surface polarity. Promising $\mathrm{CN}$ materials with high RhB degradation of $85 \%$ within $25 \mathrm{~min}$ and high surface polarity of 0.89 were selected for an immobilization approach to obtain coatings on a silicone substrate using a high-volume low-pressure (HVLP) spray coating technique. To study the photocatalytic activity of the catalyst coatings, the degradation rates of an aqueous RhB solution and solutions of organic pollutants such as triclosan and ethinyl estradiol were examined. Pollutants are decomposed with up to $63 \%$ of the initial concentration. Xenon lamps and different LEDs were used as light sources for comparison. Particularly high degradation efficiencies were obtained using LEDs, and the degradation rates are increased by adjusting the emission spectrum of the lamp to the pollutant and absorption edge of the catalyst, which results in a 40 times higher degradation efficiencies of LEDs compared to a Xe lamp.
\end{abstract}

Handling Editor: Maude Jimenez.

Address correspondence to E-mail: michael.mehring@chemie.tu-chemnitz.de 


\section{GRAPHICAL ABSTRACT}

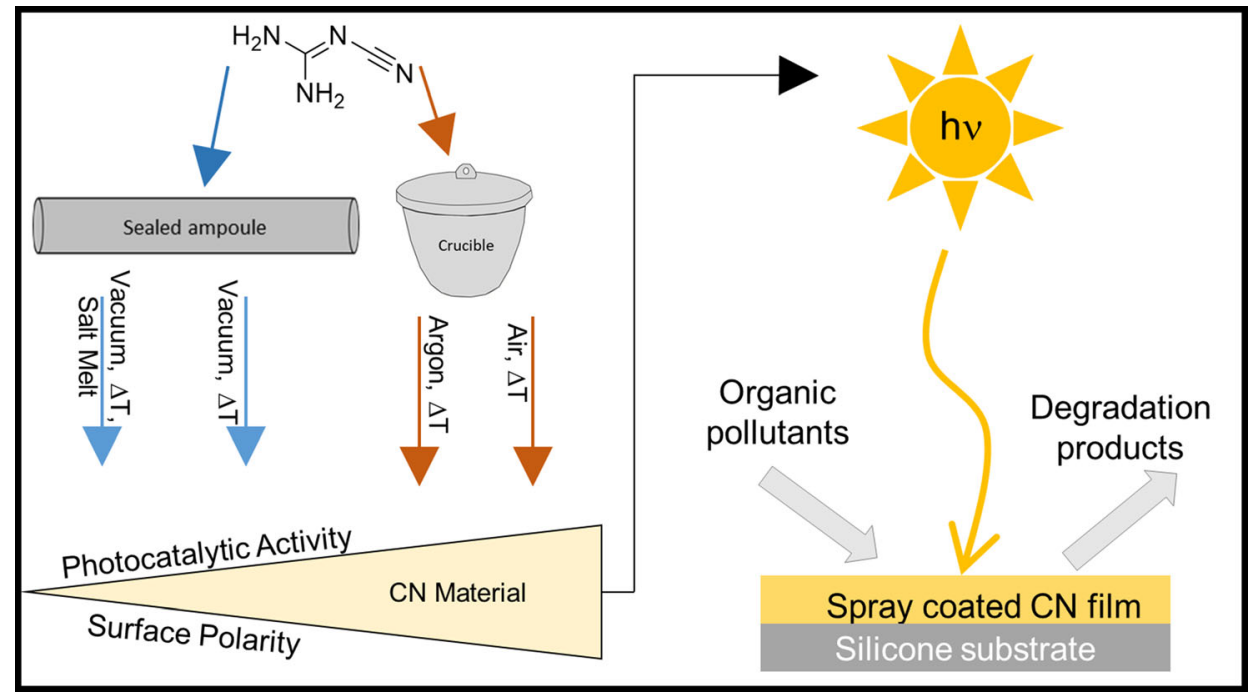

\section{Introduction}

The use of pharmaceuticals, biocides and dyes increased in the last decades, e.g., the consumption of antibiotics showed an increase by 35\% between 2000 and 2010 [1]. The use and thus the irresponsible disposal of these organic compounds contribute significantly to environmental pollution and drinking water contamination worldwide [2]. Increased exposure of ethinyl estradiol (EE2), which is used as an active ingredient in the contraceptive pill, to fish and amphibians affects live in several ways: feminization of male animals, behavioral disorders and organ damage were observed [3]. Another water contaminant represents triclosan, which is frequently used in surgical soaps and lotions, but also in toothpaste as a disinfectant. It has been detected in urine samples in Australia, the USA and China. Triclosan is suspected of affecting fertility in humans, as well as promoting food intolerances and asthma [4-6].

The degradation of these pollutants is therefore an important research goal in water purification. AOPs (advanced oxidation processes) can be applied in wastewater treatment plants to oxidise hazardous organic compounds by use of UV irradiation, ozone, hydrogen peroxide and combined methods. The potential of AOPs to decompose pollutants to $\mathrm{CO}_{2}$ and $\mathrm{H}_{2} \mathrm{O}$ is widely recognized, but the high costs for the total oxidation of pollutants limits their practical application [7-9]. Therefore, the decomposition of hazardous organic pollutants such as dyes, biocides, organic pesticides and pharmaceutical residues using heterogeneous visible light photocatalysis is becoming a promising alternative to AOPs $[7,10,11]$. The heterogeneous photocatalytic process for wastewater treatment has some decisive advantages over the AOP such as lower operating costs [12]. In this field $\mathrm{TiO}_{2}$ (band gap Anatas $3.2 \mathrm{eV}$ ) is a commonly used photocatalyst, but $\mathrm{TiO}_{2}$ uses only $4 \%$ of the solar spectrum for photocatalytic reactions [11-13]. Therefore, materials with a band gap in the visible light region are intensively sought for photocatalytic degradation of pollutants [14, 15].

We focus on the use of carbon nitride materials $(\mathrm{CN})$, which show a band gap of approximately $2.7 \mathrm{eV}$, as potential photocatalyst in water purification systems. CNs have received much attention recently, because they can be prepared from earth abundant materials, do not contain a metal and are 
environmentally benign $[13,16]$. They show a unique long-term stability, suitable band gap and are therefore promising candidates for photocatalytic applications [17, 18]. Carbon nitrides can be easily synthesized by the use of inexpensive precursors such as melamine, dicyandiamide or urea [19-21]. However, the materials obtained differ in properties, originating from the different synthetic processes, respectively, from subtle changes of the final structures $[18,22,23]$.

For photocatalytic applications $\mathrm{CN}$ with a melon like structure is a widely examined system, but with main focus on water-splitting. Melon consists of melamine-based $\mathrm{C}_{6} \mathrm{~N}_{7}$ structural units (1; Scheme 1), which have a higher thermodynamic and thermal stability than triazine units $\left(\mathrm{C}_{3} \mathrm{~N}_{3}\right)[17,23]$. The heptazine units of melon are connected to polymer strands (2a, 2b; Scheme 1). The melon structure, which is also known as Liebig's melon, is often described as a graphitic carbon nitride with the corresponding formula $\mathrm{C}_{3} \mathrm{~N}_{4}$. This description is somehow misleading and originates from the structural similarity of graphite and carbon nitride $\left(\mathrm{C}_{3} \mathrm{~N}_{4}\right)$, both showing up with a $2 \mathrm{D}$ structure. However, the terminology does not reflect the different bonding characteristics of melon and graphite. As described by Lotsch et al. the stacking between layers of carbon nitride materials is caused by hydrogen bonding between amino groups of melon strands.
Noteworthy, the perfect stoichiometric $\mathrm{C} / \mathrm{N}$ ratio of 0.75 for $\mathrm{C}_{3} \mathrm{~N}_{4}$ (3a, $\mathbf{3} \mathbf{b}$; Scheme 1) has not been achieved so far [24-26]. There is no precise and uniform nomenclature for $\mathrm{CN}$ materials. Lotsch et al. therefore proposed the term of a defect-rich graphitic carbon nitride, while Rahman et al. proposed the term of a polymeric carbon nitride [24, 26-28]. Most $\mathrm{CN}$ materials include a low amount of hydrogen of approximately $1.5 \omega \%$ and have a $\mathrm{C} / \mathrm{N}$ ratio of approximately 0.68 , which is characteristic for melonbased materials. Beside the heptazine-based $\mathrm{CN}$ materials, triazine-based $\mathrm{CN}$ materials have also been reported. The common synthesis path for these materials is the thermal decomposition of a suitable precursor in a salt melt, which provides polytriazine imides $\left(\mathrm{PTI} / \mathrm{Li}^{+} \mathrm{Cl}^{-}\right)$with intercalated ions such as $\mathrm{Li}^{+}$and $\mathrm{Cl}^{-}$ions (4; Scheme 1) [18, 23, 26, 29-31].

To obtain either heptazine-based or triazine-based $\mathrm{CN}$ materials various synthesis paths are reported in the literature. The thermal decomposition of melamine or dicyandiamide in a crucible with a lid to prevent sublimation and the decomposition in sealed ampoules with or without the use of salt melts are the most frequently used routes [18, 25, 33-35]. Bojdys et al. and Algara-Siller et al. described the formation of crystalline carbon nitride by decomposition of dicyandiamide in a salt melt, while the as-prepared product contains traces of lithium ions and chloride<smiles></smiles>

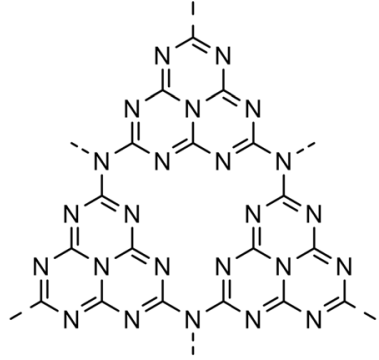

$3 a$

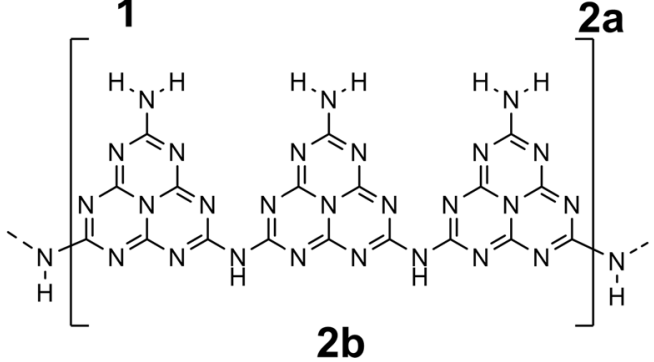

Scheme 1 Structures of melamine (1) and different structure models for a melon networks ( $2 \mathbf{a}$ and $\mathbf{2 b}$ ); structure models for a graphitic carbon nitride based on heptazine building blocks (3a)
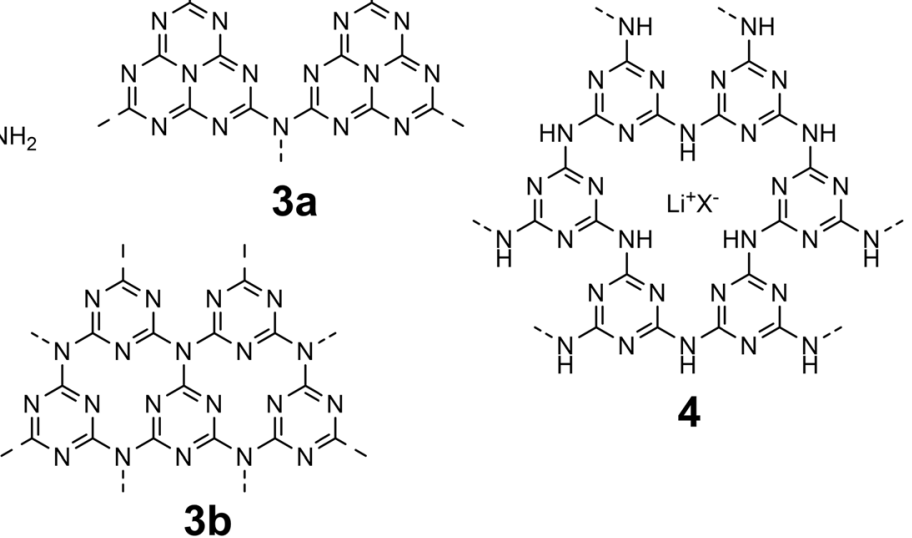

and triazine building blocks ( $3 \mathbf{b})$, with lithium ions and $\mathrm{X}=\mathrm{Cl}$ - or $\mathrm{Br}$ - intercalated in triazine-based carbon nitride (4) [26, 29, 32]. 
(4; Scheme 1) and the building blocks consist of triazine units [22, 28, 31, 36]. Wang et al. described that a higher degree of condensation and therefore a high crystallinity was obtained for carbon nitrides that were prepared via thermal decomposition of dicyandiamide in sealed ampoules with and without the use of a salt melt. However, most of the photocatalytic degradation experiments were carried out with defect-rich, less crystalline and more active carbon nitrides consisting of heptazine units. Thus, it is concluded that surface termination seems to be an important factor with regard to active sites, [37] but studies comparing differently prepared materials are not reported so far.

We focus on a comparison of the photocatalytic efficiency of differently prepared $\mathrm{CN}$ materials with regard to the photocatalytic degradation of pollutants in water. The $\mathrm{CN}$ materials were synthesized via four different synthesis routes, the thermal decomposition of dicyandiamide in a crucible (air vs. argon atmosphere) and sealed ampoules as well as in sealed ampoules with use of a flux medium. To investigate the different chemical properties, UV-Vis spectroscopy, elemental analysis, IR spectroscopy, powder X-ray diffraction and NMR spectroscopy were used. The surface polarity was estimated by adsorption of the dye dicyano-bis(1,10-phenanthroline)-iron(II) $\left(\left[\mathrm{Fe}(\text { phen })_{2}(\mathrm{CN})_{2}\right]\right)$. This allows conclusions to be made concerning the adsorption of pollutants to the catalyst surface [38]. The CN materials were tested for their capability to degrade aqueous $\mathrm{RhB}$, which shows absorbance in the visible light region. $\mathrm{CN}$ materials with the highest potential for the photocatalytic degradation of pollutants were selected for an immobilization approach. In the literature, degradation processes are usually evaluated by means of dispersions of the photocatalyst [13, 39-42]. Generally, dispersions show significant higher activities than immobilized particles, but to avoid the phase separating process of catalyst particles in an industrial approach, it is essential to establish immobilization methods. Thus, the challenge for immobilization of photocatalysts is attracting increasing attention $[43,44]$. We have chosen the HVLP spray coating technique which is easy to handle, has low acquisition costs and is transferable to other photocatalyst materials. The prepared coatings were used to study the degradation rate of an aqueous $\mathrm{RhB}$ solution with regard to different applied catalyst masses. Selected films were used for the degradation of triclosan and ethinyl estradiol and the influence of different light sources on the degradation mechanism and degradation rates was investigated.

\section{Results and discussion}

\section{Preparation and characterization of the photocatalysts}

In a first step several carbon nitride materials were prepared for a comparative photocatalytic study. First, a condensation reaction of dicyandiamide at $550{ }^{\circ} \mathrm{C}$ and $600{ }^{\circ} \mathrm{C}$ with variation of time $(4 \mathrm{~h}$ and $12 \mathrm{~h}$ ) was carried out in ambient atmosphere $\left(\mathrm{CN}_{550}-\mathrm{C} 4, \mathrm{CN}_{550}-\mathrm{C12}, \mathrm{CN}_{600}-\mathrm{C} 4, \mathrm{CN}_{600}-\mathrm{C12}\right)$ and under argon $\left(\mathbf{C N}_{550}-\mathbf{T 4} / \mathbf{A r}\right)$. This method is expected to provide defect rich $\mathrm{CN}$ materials mainly consisting of heptazine units $[31,37,45]$. The same parameters (temperature, time) were used for a second set of samples using sealed ampoules $\left(\mathbf{C N}_{550}-\mathbf{A 4}, \mathbf{C N}_{550}-\mathbf{A 1 2}\right.$, $\mathbf{C N}_{600}-\mathbf{A 4}, \mathbf{C N}_{600}-\mathbf{A 1 2}$ ), a synthetic path which should provide highly ordered heptazine-based networks [26]. In a fourth approach the synthesis is carried out in lithium chloride/potassium chloride melt at $600{ }^{\circ} \mathrm{C}$ starting from dicyandiamide $(\mathbf{C N}-\mathbf{M})$. This method was reported to yield triazine-based $\mathrm{CN}$ materials which show intercalation of $\mathrm{LiCl}$ [36].

The XRD patterns of $\mathbf{C N}-\mathbf{C}$ and $\mathbf{C N}-\mathbf{A}$ samples exhibit two characteristic reflections at $2 \theta=12.9^{\circ}$ and $2 \theta=27.6^{\circ}$ and fit to the reference for heptazine-based

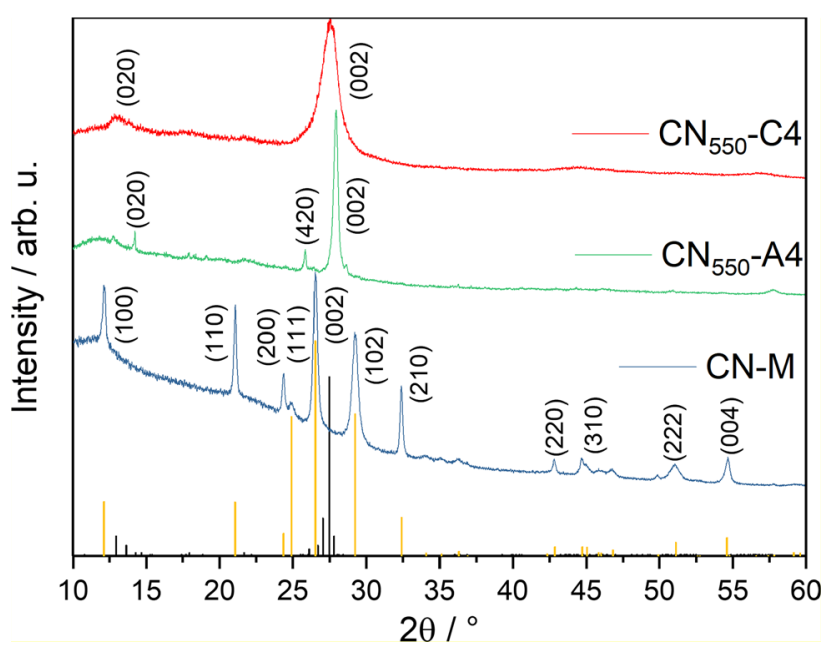

Figure 1 XRD pattern of selected samples $\mathrm{CN}_{550}-\mathrm{C} 4, \mathrm{CN}_{550}-$ A4, CN-M, heptazine-based $\mathrm{CN}$ reference (black bars) ICDD 00-066-0813[25] and reference for triazine-based CN materials with intercalated ions (yellow bars) [31]. 
$\mathrm{CN}$ materials (Fig. 1, SI 1). The main reflex at $2 \theta=27.6^{\circ}$ is reported for the (002) plane and describes the distance between the layers of the material [25-27]. For $\mathbf{C N}-\mathbf{A}$ samples a slight shift to $2 \theta=27.9^{\circ}$ compared to the reference is observed. A higher crystallinity for $\mathbf{C N}-\mathbf{A}$ as compared to $\mathbf{C N}-$ $\mathbf{C}$ is in agreement with literature data. Additional reflexes at $2 \theta=14.2^{\circ}$ and $2 \theta=25.8^{\circ}$ represent reflection for the (020) and the (420) plane, respectively $[26,37,42]$. The XRD pattern and the intensity distribution of the reflexes of $\mathbf{C N}-\mathbf{M}$ is also in accordance with literature values [31,36] and are clearly distinguished from those of $\mathbf{C N}-\mathbf{C}$ and $\mathbf{C N}-\mathbf{A}$ samples. The reasons are intercalation of the flux medium and formation of an amine-linked carbon nitride material based on triazine units [18, 30, 31, 36].

The empirical formula of $\mathrm{C}_{6} \mathrm{~N}_{9} \mathrm{H}_{3}$ is provided for melon polymers, which is in accordance with our data from elemental analysis for $\mathbf{C N}-\mathbf{C}$ and $\mathbf{C N}-\mathbf{A}$ (SI 2) $[26,28]$. The $\mathrm{C} / \mathrm{N}$ ratio is given with $0.64-0.68$, the hydrogen content is in the range of 1.6-1.7 $\omega \%$, which is in accordance with reported values. [25-27, 46, 47] The elemental analysis of $\mathbf{C N}-\mathbf{M}$ differs significantly from the values for $\mathbf{C N}-\mathbf{C}$ and $\mathbf{C N}-\mathbf{A}$. The carbon and nitrogen contents are lower as a result of the incorporation of lithium chloride, and the hydrogen content in $\mathbf{C N}-\mathbf{M}$ is much lower due to a higher degree of condensation. The values are in agreement with the literature $[18,22,31]$.

The higher degree of condensation of $\mathbf{C N}-\mathbf{M}$ was confirmed by ATIR spectroscopy (Fig. 2, SI 3). A band of comparatively low intensity between 3500 and $3000 \mathrm{~cm}^{-1}$ corresponds to bridging $\mathrm{NH}$ groups. In

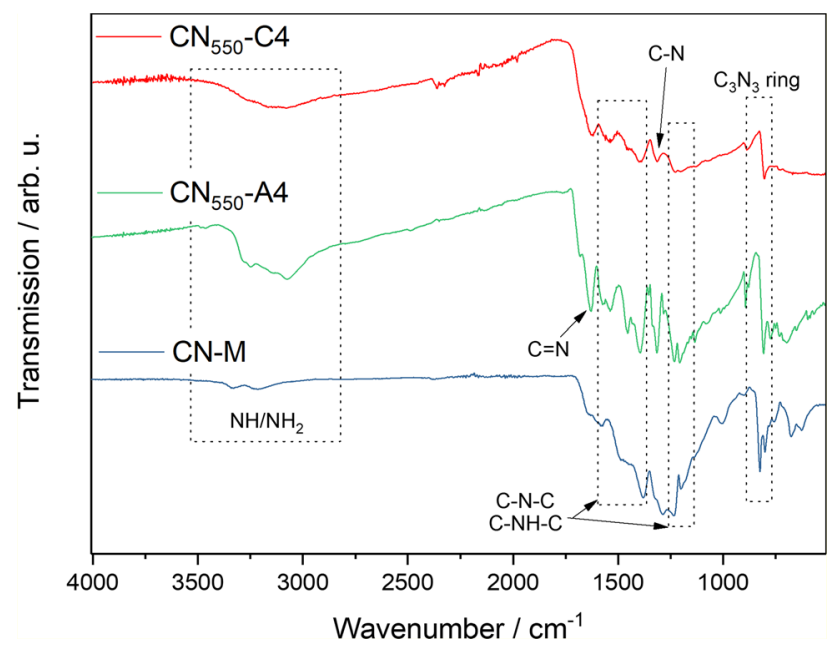

Figure 2 ATIR spectra of selected samples $\mathrm{CN}_{550}-\mathrm{C4}, \mathrm{CN}_{550}-$ A4 and $\mathrm{CN}-\mathrm{M}$. comparison with $\mathrm{CN}$ materials, which consist of heptazine units and thus show both $\mathrm{NH}$ and $\mathrm{NH}_{2}$ groups, the $\mathrm{NH}$ band in $\mathbf{C N}-\mathbf{M}$ is much less pronounced and sharp, which is assigned to the high degree of condensation [18, 31]. CN-A samples show sharper bands than $\mathbf{C N}-\mathbf{C}$, which is assigned to their higher structural order. This agrees with the XRD analysis. The ATIR spectra for $\mathbf{C N}-\mathbf{A}$ and $\mathbf{C N}-\mathbf{C}$ are consistent with the literature data [26, 42]. Broad bands between 3500 and $3000 \mathrm{~cm}^{-1}$ indicate $\mathrm{NH}$ or $\mathrm{NH}_{2}$ groups. The range between $1200-1100 \mathrm{~cm}^{-1}$ and $1600-1350 \mathrm{~cm}^{-1}$ is assigned to the uncondensed C$\mathrm{NH}-\mathrm{C}$ bands and condensed $\mathrm{C}-\mathrm{N}-\mathrm{C}$ networks. Bands at $1315 \mathrm{~cm}^{-1}$ are allocated to the $\mathrm{C}-\mathrm{N}$ stretching modes. At $1630 \mathrm{~cm}^{-1}$ bands for $\mathrm{C}=\mathrm{N}$ stretching modes are present. The characteristic bands of $\mathrm{C}_{3} \mathrm{~N}_{3}$ rings are observed at $810 \mathrm{~cm}^{-1}$. $[18,26,30,33]$ The IR spectra cannot be used to differentiate between the individual heptazine or triazine networks, which makes solid-state NMR spectroscopy necessary [36].

The solid-state ${ }^{13} \mathrm{C}\left\{{ }^{1} \mathrm{H}\right\}-\mathrm{CP}-\mathrm{MAS}-\mathrm{NMR}$ spectra provide an indication for the structure of the basic building blocks (Fig. 3, SI 4). For $\mathbf{C N}-\mathbf{C}$ and $\mathbf{C N}-\mathbf{A}$, two signals are observed at $157 \mathrm{ppm}$ and $165 \mathrm{ppm}$. These values are consistent with literature data [26] obtained for melem and for CN materials accessible via the synthesis method used here. The signal at $157 \mathrm{ppm}$ is assigned to the $\mathrm{CN}_{3}$ unit and the signal at $165 \mathrm{ppm}$ to the carbon atom bound to the amino groups. It is concluded that the as-prepared $\mathrm{CN}$ materials are composed of the thermodynamically

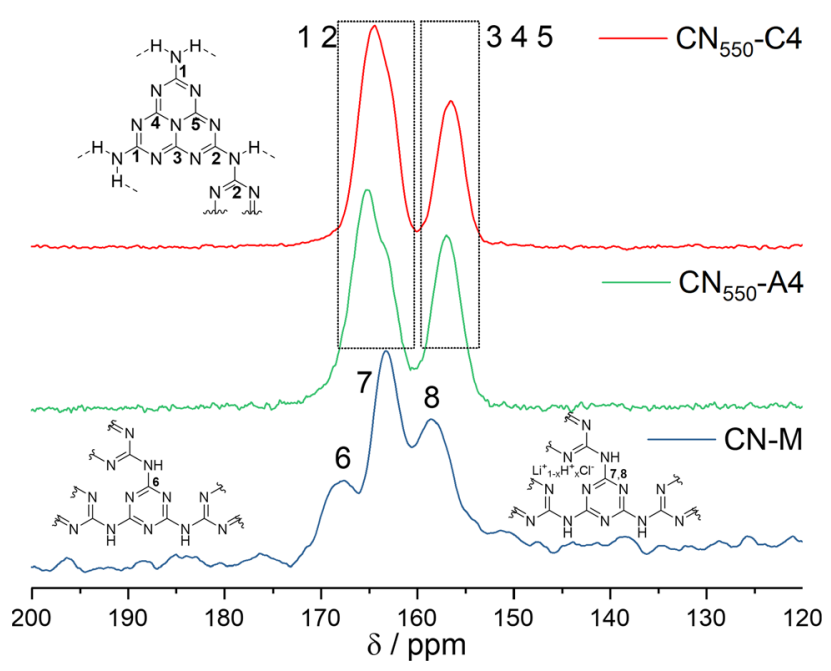

Figure $3{ }^{13} \mathrm{C}\left\{{ }^{1} \mathrm{H}\right\}$-CP-MAS-NMR of selected samples $\mathbf{C N}_{550}$ C4, $\mathrm{CN}_{550}-\mathrm{A} 4$ and $\mathrm{CN}-\mathrm{M}\left(\mathrm{PTI} / \mathrm{Li}^{+} \mathrm{Cl}^{-}\right)$. 
stable heptazine units. This is also consistent with the data of the elemental analyses [23, 26, 31]. The shoulder at $163 \mathrm{ppm}$ in $\mathbf{C N}-\mathbf{A}$ is explained by differently linked structures of the adjacent nitrogen atoms, whereby simultaneous interactions via hydrogen bonds between the melon strands and a linkage to other heptazine units are present [26]. The spectrum of $\mathbf{C N}-\mathbf{M}$ differs from the others and is in agreement with reports of Wirnhier et al.[36] According to the literature, the PTI $/ \mathrm{Li}^{+} \mathrm{Cl}^{-}$structure includes $\mathrm{Li}^{+}$and $\mathrm{Cl}^{-}$which are located in the voids between the NH-bridged triazine rings. Due to the stacking of the 2D layers, channels containing the intercalated ions are formed. The $\mathrm{Cl}^{-}$is located in the center of these channels and surrounded by $\mathrm{Li}^{+}$. Due to structural disorder, $\mathrm{Li}^{+}$is partly replaced by $\mathrm{H}^{+}$ ions which protonates the $\mathrm{N}$ atom of the triazine rings. This results in a different chemical environment for the carbon atom of the triazine rings. This disorder is represented by two different signals at $158 \mathrm{ppm}$ and $163 \mathrm{ppm}$ for these carbon atoms. Carbon atoms adjacent to non-protonated triazine rings show a signal at $167 \mathrm{ppm}$ which corresponds to literature data for triazine-based $\mathrm{CN}$ networks $[30,36,48]$.

A comparison of the specific surface area of the different $\mathrm{CN}$ materials shows an increase in the BET surface area with increasing synthesis temperature and a minor increase with increasing reaction time (Table 1, SI 5). The increased surface area is explained by a slightly increasing pore volume (SI 6) due to the higher amount of $\mathrm{NH}_{3}$ release upon longer reaction times and higher reaction temperatures.

$\mathrm{CN}-\mathrm{C}$ materials have a light yellow color, the $\mathrm{CN}-$ A materials are beige and the product $\mathbf{C N}-\mathbf{M}$ is dark

Table 1 BET surface areas and calculated band gaps of the asprepared $\mathrm{CN}$ materials

\begin{tabular}{lll}
\hline Sample & BET surface area $/ \mathrm{m}^{2} \mathrm{~g}^{-1}$ & Band gap/eV \\
\hline $\mathrm{CN}_{550}-\mathrm{C} 4$ & 18 & 2.8 \\
$\mathrm{CN}_{550}-\mathrm{C} 12$ & 20 & 2.8 \\
$\mathrm{CN}_{600}-\mathrm{C} 4$ & 40 & 2.8 \\
$\mathrm{CN}_{600}-\mathrm{C} 12$ & 41 & 3.0 \\
$\mathrm{CN}_{550}-\mathrm{A} 4$ & 14 & 2.9 \\
$\mathrm{CN}_{550}-\mathrm{A} 12$ & 23 & 3.0 \\
$\mathrm{CN}_{600}-\mathrm{A} 4$ & 26 & 2.9 \\
$\mathrm{CN}_{600}-\mathrm{A} 12$ & 31 & 3.0 \\
$\mathrm{CN}-\mathrm{M}$ & 44 & 3.1 \\
\hline
\end{tabular}

brown. The absorption edges were estimated by UVVis spectroscopy (SI 7). Based on the UV-Vis spectra the band gaps were determined using Tauc plots (Table 1, SI 8). For $\mathbf{C N}-\mathbf{C}$, the band gaps are at $2.8 \mathrm{eV}$. The presented data are in good agreement with the literature $[47,49,50]$. The $\mathbf{C N}-\mathbf{A}$ materials show a band gap of ca. $3.0 \mathrm{eV}$. For $\mathbf{C N}-\mathbf{M}$ a band gap of $3.1 \mathrm{eV}$ is determined [18, 51]. Therefore, all synthesized catalysts are suitable for excitation with visible light.

To get a better idea of the degree of $\mathrm{NH}$-condensation for the samples-at least at the surface-the surface polarity was investigated. Estimation of the ability to provide hydrogen bonds as a hydrogen bond donor $(\mathrm{HBD})$ is possible by adsorbing the dye $\left[\mathrm{Fe}(\text { phen })_{2}(\mathrm{CN})_{2}\right]$ onto the particle surface [38]. The shift of the UV-Vis absorption band $\lambda_{\max }$ is used to calculate the HBD ability $\alpha$ according to Eq. (3). The HBD ability may influence the photocatalytic activity, since polar amino groups are reported to be the active sites in $\mathrm{CN}$ materials [37]. To ensure that only a thin layer of the dye is adsorbed, different concentrations were used to investigate the resulting shift exemplary for sample $\mathbf{C N}_{550}$-C4 (Fig. 4). With a higher dye concentration of $1.2 \mathrm{mg} \mathrm{g}^{-1}$, a bathochromic shift is observed which is attributed to those complexes $\left[\mathrm{Fe}(\text { phen })_{2}(\mathrm{CN})_{2}\right]$, which are not adsorbed. The absorption maxima $\lambda_{\max }$ for concentrations of $0.6 \mathrm{mg} \mathrm{g}^{-1}$ and $0.3 \mathrm{mg} \mathrm{g}^{-1}$ differ only slightly; therefore, a mass concentration of $0.3 \mathrm{mg}_{\left[\mathrm{Fe}(\text { phen })_{2}(\mathrm{CN})_{2}\right] /} 1 \mathrm{~g}_{\text {catalyst }}$ is used for further experiments.

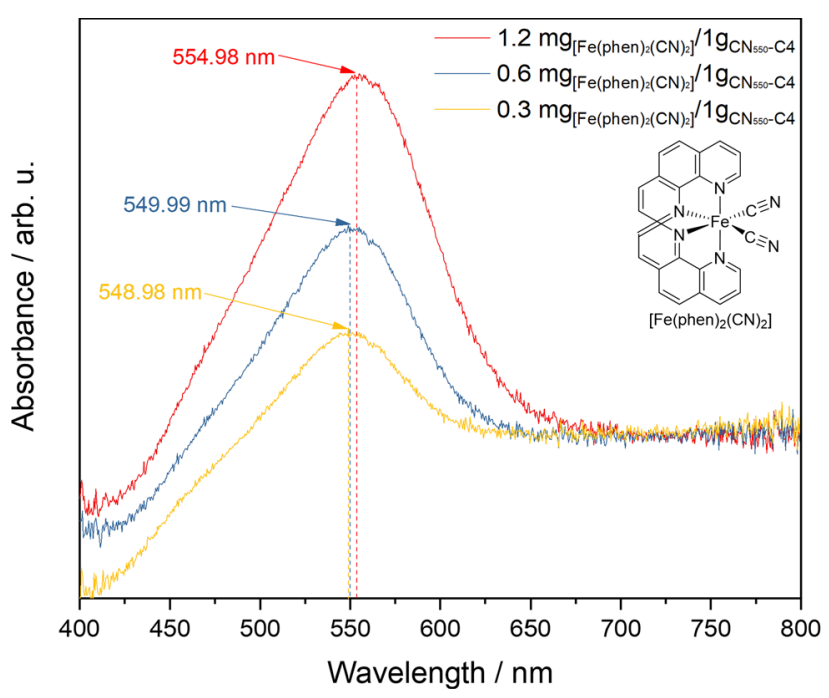

Figure 4 Solid-state UV-Vis spectra of $\mathbf{C N}_{550}-\mathbf{C} 4$ with different amounts of added $\left[\mathrm{Fe}(\mathrm{phen})_{2}(\mathrm{CN})_{2}\right]$. 
Table 2 Absorption maxima for $\mathrm{CN}$ materials and calculated $\alpha$ values in comparison with some literature data

\begin{tabular}{lcl}
\hline Sample & $\lambda_{\max } / \mathrm{nm}$ & $\alpha$ \\
\hline $\mathrm{TiO}_{2}$ (Rutile) & - & $1.48[38]$ \\
$\mathrm{TiO}_{2}$ (Anatase) & - & $1.41[38]$ \\
$\mathrm{CaCO}_{3}$ & - & $0.78[38]$ \\
$\mathrm{MgO}$ & - & $0.67[38]$ \\
$\mathrm{CN}_{550}-\mathrm{C} 4$ & 548.98 & 0.89 \\
$\mathrm{CN}_{550}-\mathrm{C} 12$ & 557.22 & 0.77 \\
$\mathrm{CN}_{600}-\mathrm{C} 4$ & 552.51 & 0.84 \\
$\mathrm{CN}_{600}-\mathrm{C} 12$ & 556.48 & 0.78 \\
$\mathrm{CN}_{550}-\mathrm{A} 4$ & 555.49 & 0.79 \\
$\mathrm{CN}_{550}-\mathrm{A} 12$ & 555.51 & 0.79 \\
$\mathrm{CN}_{600}-\mathrm{A} 4$ & 564.98 & 0.65 \\
$\mathrm{CN}_{600}-\mathrm{A} 12$ & 577.48 & 0.48 \\
$\mathrm{CN}_{-} \mathrm{M}$ & 554.98 & 0.80 \\
\hline
\end{tabular}

The values for the absorption maxima and the calculated $\alpha$ values are summarized in Table 2 . The highest value $\alpha$ is calculated for sample $\mathbf{C N}_{550}-\mathbf{C 4}$. Compared to $\mathrm{TiO}_{2}$ [11] with $\alpha$ values of 1.41 , the HBD of the $\mathrm{CN}$ materials is lower and is found in the area of $\alpha$ values as reported for $\mathrm{CaCO}_{3}$ and $\mathrm{MgO}$, which range between 0.48 and 0.84 [38]. Higher $\alpha$ values are obtained for $\mathrm{CN}$ materials as prepared with shorter reaction times and lower reaction temperatures. These CN materials tend to show a lower degree of condensation and therefore a higher amount of uncondensed polar amino groups.

\section{Photocatalytic behavior of the $\mathrm{CN}$ materials}

To evaluate the photocatalytic performance of the different $\mathrm{CN}$ materials, the degradation rates of an aqueous RhB solution using a $300 \mathrm{~W}$ Xe lamp were measured first (Fig. 5). CN-C enable higher photocatalytic degradation rates than $\mathbf{C N}-\mathbf{A}$ and $\mathbf{C N}-$ $\mathbf{M}$ with up to $85 \% \mathrm{RhB}$ degradation within $25 \mathrm{~min}$ for sample $\mathbf{C N}_{550}-\mathbf{C 4}$. The degradation rates for $\mathbf{C N}_{550^{-}}$ C12, $\mathbf{C N}_{600}-\mathrm{C} 4$ and $\mathbf{C N}_{600}-\mathbf{C 1 2}$ are slightly lower compared to $\mathrm{CN}_{550}-\mathrm{C} 4$. Since the same reaction setup and the same catalyst mass were used for the measurements performed here, the conversion is equivalent to the activity, and thus the highest photocatalytic activity is determined for $\mathbf{C N}_{550}-\mathbf{C} 4$. $\mathbf{C N}-\mathbf{A}$ materials and $\mathbf{C N}-\mathbf{M}$ (Fig. 5) all show lower photocatalytic activities than $\mathrm{CN}-\mathrm{C}$ materials. The highest degree of conversion of the $\mathbf{C N}-\mathbf{A}$ samples was measured for $\mathbf{C N}_{\mathbf{5 5 0}}-\mathbf{A} 4$. It degrades $87 \% \mathrm{RhB}$ within $150 \mathrm{~min}$ irradiation time. $\mathbf{C N}-\mathbf{M}$ degrades only $10 \%$ within $150 \mathrm{~min}$; thus, the triazine-based $\mathbf{C N}-\mathbf{M}$ shows the lowest photocatalytic activity. A slight hypsochromic shift, of the RhB absorption maximum during the degradation process caused by a stepwise de-ethylation, is observed for all CN materials, which is indicative for a photosensitive degradation mechanism (SI 9) $[52,53]$.

The photocatalytic activity of the $\mathrm{CN}$ materials is related to the structure formed as a result of different synthesis parameters. Materials of lower crystallinity like the $\mathrm{CN}-\mathrm{C}$ materials have, compared to $\mathbf{C N}-\mathbf{A}$ and $\mathbf{C N}-\mathbf{M}$, an increased number of defects which influence the photocatalytic properties [17, 37]. Sample $\mathbf{C N}_{600}-\mathbf{C 4}$ and $\mathbf{C N}_{600}-\mathbf{C 1 2}$ adsorb twice as much $\mathrm{RhB}$ by stirring in the dark than the other $\mathrm{CN}-\mathrm{C}$ samples, as a result of both their doubled specific surface area compared to, e.g., $\mathrm{CN}_{550}-\mathrm{C} 4$ and a tendency toward higher surface polarity compared to $\mathbf{C N}-\mathbf{A}$ samples. Higher BET surface areas correlate with the adsorption capacity, but do not result in a higher photocatalytic activity. This trend is obvious for $\mathbf{C N}-\mathbf{A}$ samples (SI 10). Noteworthy, $\mathbf{C N}-\mathbf{M}$ shows a high HBD and BET surface area, but negligible photocatalytic activity compared to $\mathrm{CN}-\mathrm{C}$. Even $\mathrm{CN}$ materials with a low BET surface area such as $\mathrm{CN}_{550}-\mathrm{C} 4$ show high photocatalytic $\mathrm{RhB}$ degradation rates, and it is concluded that the surface area does not determine the photocatalytic activity in first instance. This is confirmed by comparison of materials with similar BET surface areas but different HBD. $\mathbf{C N}-\mathbf{A}$ and $\mathbf{C N}-\mathbf{M}$ were synthesized in vacuum and showed quite low photocatalytic activity, while highly photocatalytic active samples $(\mathrm{CN}-\mathrm{C})$ were obtained in air (SI 10). For comparison a material synthesized analogously to $\mathbf{C N}_{550}-\mathbf{C 4}$, but in argon atmosphere was prepared $\left(\mathbf{C N}_{550}-\mathbf{C} 4 / \mathbf{A r}\right.$, SI 11$)$. Crystallinity, band gap, elemental analysis and the BET surface area do not differ significantly. However, the HBD of $\mathbf{C N}_{550}-\mathbf{C 4} / \mathbf{A r}$ amounts to 0.59, which is significantly lower than the value of 0.89 for $\mathbf{C N}_{550}-\mathbf{C 4}$ and indicates lower surface polarity. In a similar manner the photocatalytic degradation rates of RhB with $\mathrm{CN}_{550}-\mathrm{C} 4$ and $\mathrm{CN}_{550}-\mathrm{C} 4 / \mathrm{Ar}$ and the adsorption behavior during the dark phase differ significantly from each other. $\mathbf{C N}_{550}-\mathbf{C 4} / \mathbf{A r}$ degrades 92\% RhB within 120 min irradiation time and adsorbs $5 \% \mathrm{RhB}$ in the dark phase while $\mathrm{CN}_{550}-\mathrm{C} 4$ adsorbs $15 \%$ and degrades the RhB almost fully within $25 \mathrm{~min}$. Therefore, it is concluded that the surface 
(a)

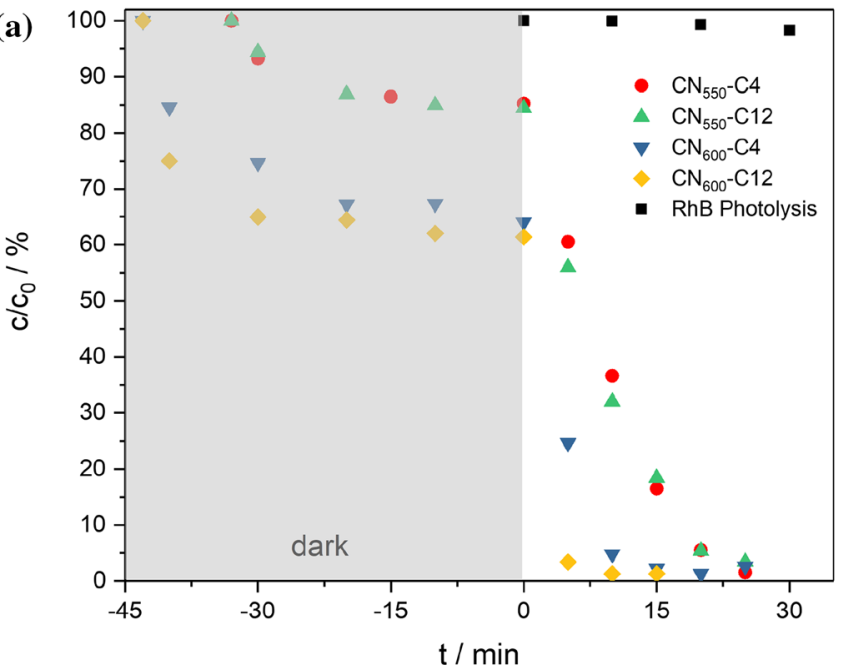

Figure 5 Time-dependent photodegradation of an aqueous $\mathrm{RhB}$ solution $\left(1 \times 10^{-5} \mathrm{M}\right)$ under visible light irradiation with an $300 \mathrm{~W}$ Xe lamp $(t>0 \mathrm{~min})$ without catalyst and in the presence

polarity influences the adsorption behavior between the dye and the catalyst surface and a high HBD contributes adsorption interactions between the pollutant and the catalyst surface. This is of particular interest when photosensitive degradation mechanisms occur, since the adsorption behavior of the dye onto the catalyst surface is a key factor for these processes. In addition, the existence of polar groups on the catalyst surface seems beneficial to promote high photocatalytic activity. For this reason, the evaluation of the HBD ability is useful. It provides indirect information on the degree of condensation of the $\mathrm{CN}$ materials and their surface termination by functional groups. It is shown that the photocatalytic activity and the degree of photocatalytically induced conversion correlates with parameters of the materials syntheses, increase of activity with decreasing reaction temperature and reaction time. The determination of the HBD provides analytical evidence for literature data that postulated a high impact of surface polarity and polar groups on the photocatalytic activity of $\mathrm{CN}$ materials [37, 42].

When using the $300 \mathrm{~W}$ Xe lamp as light source, photosensitive degradation mechanisms and the direct excitation of the photocatalyst materials occur simultaneously, since the emission spectrum of the Xe lamp and the absorption edge of $\mathbf{C N}_{550}-\mathbf{C} 4$ overlap (SI 12) and an additional excitation of the RhB molecule occurs. The use of $3 \mathrm{~W}$ LEDs with more distinct emission spectra might result in a change of the degradation mechanism with impact on the RhB

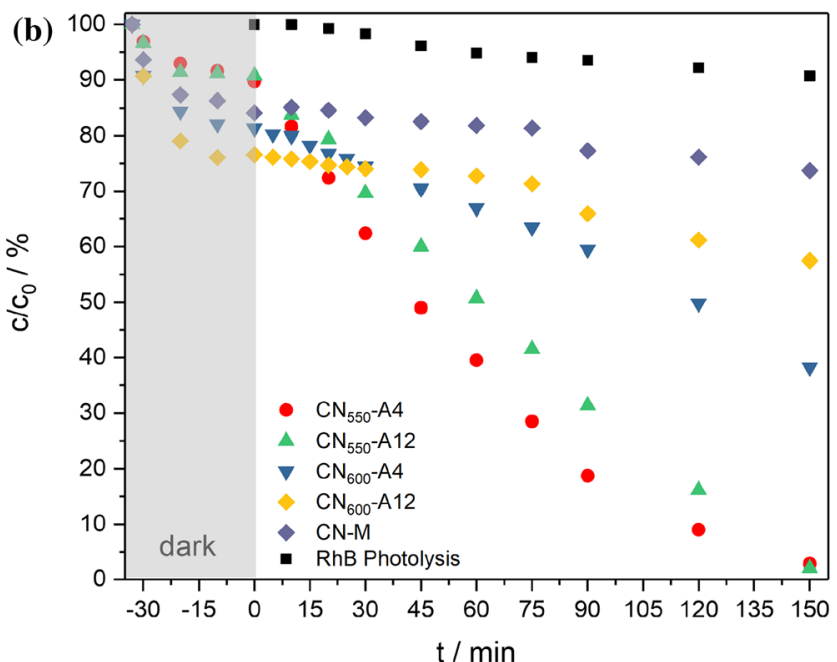

of a $\mathrm{CN}$ materials obtained by a synthesis in a crucible; $\mathbf{b} \mathrm{CN}$ materials obtained by a synthesis in sealed ampoules and $\mathrm{CN}$ material obtained by a synthesis in a salt melt.

degradation rates. Therefore, the influence of the wavelength of the LED on the degradation rate of $\mathrm{RhB}$ with $\mathrm{CN}_{550}-\mathrm{C4}$ (Fig. 6a) was investigated exemplarily, to clarify the interplay between direct photooxidation and photosensitive degradation. The comparison of the emission spectra of the LED with the absorption edge of $\mathbf{C N}_{550}-\mathbf{C 4}$ shows that a direct excitation of the catalyst material is only possible by use of the blue $470 \mathrm{~nm}$ LED (SI 12). However, the highest degradation rate is observed using the $528 \mathrm{~nm}$ LED with a degradation of $85 \% \mathrm{RhB}$ within $55 \mathrm{~min}$. The use of the $470 \mathrm{~nm}$ LED gave $69 \% \mathrm{RhB}$ degradation within $60 \mathrm{~min}$, and irradiation with a $590 \mathrm{~nm}$ LED lead to an RhB degradation of $54 \%$. Using a $625 \mathrm{~nm}$ LED gave an RhB degradation of $13 \%$ only. The stepwise de-ethylation of the RhB molecule is indicated by a hypsochromic shift of the absorption maxima of $\mathrm{RhB}$ during the degradation process by use of a $3 \mathrm{~W}$ LED (528 nm) (Fig. 6b). This shift is an evidence for photosensitive degradation mechanisms $[52,53]$. It was expected that the $470 \mathrm{~nm}$ LED, which is the best suited LED used here for the catalyst activation, should enable the highest photocatalytic degradation rate as a result of photooxidation. It shows good match of emission and excitation wavelengths of the photocatalyst. However, the green vis LED (528 nm) gave a more efficient RhB degradation, which results from excitation of the RhB molecule and thus operation of the photosensitive degradation mechanism. 


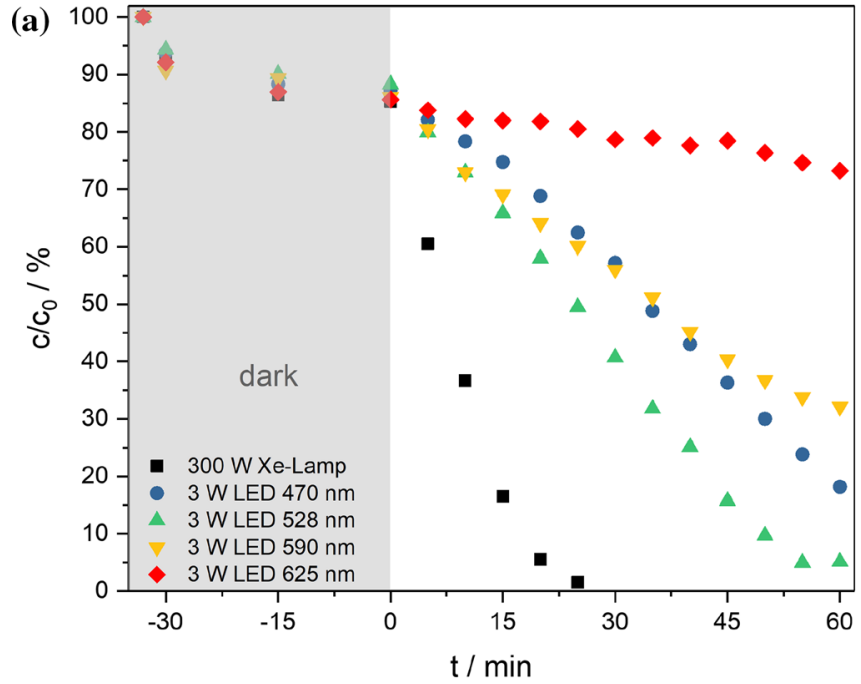

Figure 6 a Time-dependent photodegradation of an aqueous RhB solution $\left(1 \bullet 10^{-5} \mathrm{M}\right)$ under visible light irradiation with $3 \mathrm{~W}$ LEDs with different wavelengths and a $300 \mathrm{~W}$ Xe lamp $(t>0 \mathrm{~min})$

It is worth to note that the degradation rate is related to the power of the light source. Particularly efficient light sources generate high degradation rates at low powers. The calculation of energy efficiencies (SI 13) following the literature [54] shows that the $528 \mathrm{~nm}$ green LED with a value of $12.2 \mathrm{~mL} \mathrm{~W}^{-1} \mathrm{~h}^{-1}$ is about 40 times more efficient than the $300 \mathrm{~W}$ Xe lamp with $0.3 \mathrm{~mL} \mathrm{~W}^{-1} \mathrm{~h}^{-1}$. In general, the nature and influence of the light source on degradation mechanisms and excitation of a photocatalyst material has to be considered whenever different measurement setups, light sources and catalysts are compared.

\section{Spray coating of $\mathrm{CN}$ films}

With regard to the previously presented analytical data, $\mathbf{C N}_{550}-\mathbf{C} 4$ is a promising catalyst material for photocatalytic degradation reactions. It combines a suitable band gap, a high HBD and a high RhB degradation rate. Therefore, these particles are used for the immobilization approach and sprayed onto a substrate with an HVLP spray gun at 100 psi working pressure. The substrate is composed of a silicone tape which is attached on a glass substrate and placed on a heat plate during the spraying process for continuous solvent evaporation. First, different amounts of catalyst were immobilized on substrates to investigate the correlation between deposited mass, the degradation rate and the activity, respectively. Therefore, mass

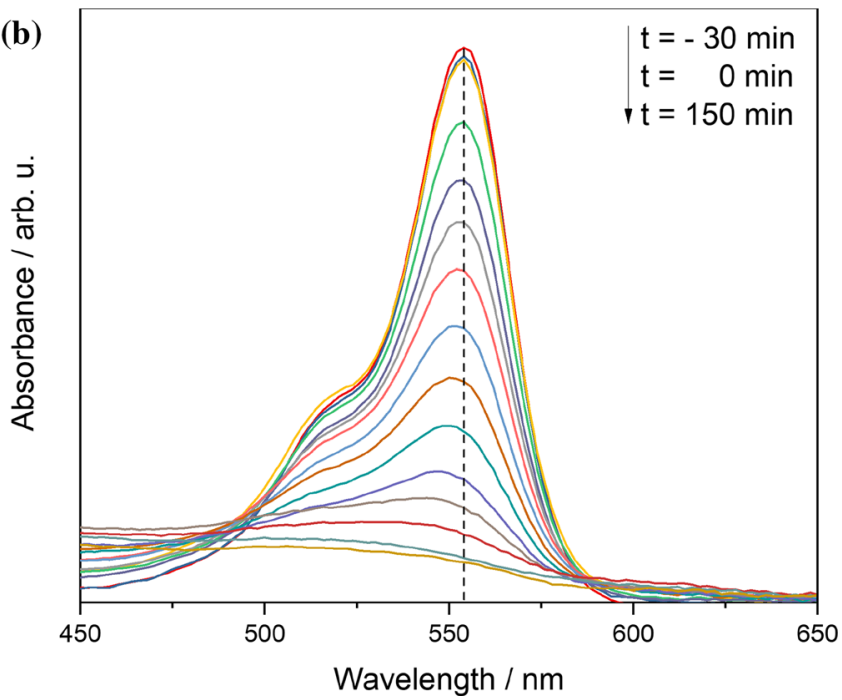

without catalyst and in the presence of the $\mathrm{CN}_{550}-\mathbf{C 4}, \mathrm{b}$ visible light spectra of RhB while photodegradation process with $\mathrm{CN}_{550}$ C4 and $528 \mathrm{~nm}$ LED.

loadings of $0.80 \mathrm{mg}(\mathrm{CN}-1), 1.39 \mathrm{mg}(\mathrm{CN}-2)$ and $2.66 \mathrm{mg}(\mathrm{CN}-3)$ were applied. The light microscope and SEM images of the as-prepared coatings (Fig. 7) show a complete coverage of the black substrates for all samples. With increasing applied particle mass, larger particle agglomerates and rough surfaces are observed.

The layer thickness was estimated by measurements of the cross section of the films (SI 14). The film thickness increases with increased deposited mass from $5 \mu \mathrm{m}(\mathbf{C N}-1)$ to $11 \mu \mathrm{m}(\mathbf{C N}-2)$ and $23 \mu \mathrm{m}$ for $\mathrm{CN}-3$.

\section{Photocatalytic degradation of organic dyes with immobilized catalyst}

To determine the photocatalytic activity, the degradation rates of $\mathrm{RhB}$ with different amounts of deposited catalyst were evaluated in a photoreactor using $35 \mathrm{~mL}$ RhB solution $\left(1 \times 10^{-5} \mathrm{M}\right)$ under visible light irradiation (Fig. 8). The highest degradation rate of $\mathrm{RhB}$ within $8 \mathrm{~h}$ irradiation time amounts to $71 \%$ and was obtained with the highest loading of the substrate $(\mathrm{CN}-3)$. Substrates $\mathbf{C N}-2$ and $\mathbf{C N}-1$ degrade $64 \% \mathrm{RhB}$ and $58 \% \mathrm{RhB}$, respectively, within the same period of time. Thus, activities of $5.2 \times 10^{-10}$ mol mg ${ }^{-1} \mathrm{~min}^{-1}$ for $\mathrm{CN}-1,3.4 \times 10^{-10} \mathrm{~mol} \mathrm{mg}^{-1}$ $\mathrm{min}^{-1}$ for $\mathrm{CN}-2$ and $1.9 \times 10^{-10} \mathrm{~mol} \mathrm{mg}^{-1} \mathrm{~min}^{-1}$ for $\mathrm{CN}-3$ were calculated. A further increase in the applied catalyst mass above $0.80 \mathrm{mg}(\mathbf{C N}-\mathbf{1})$ does not 

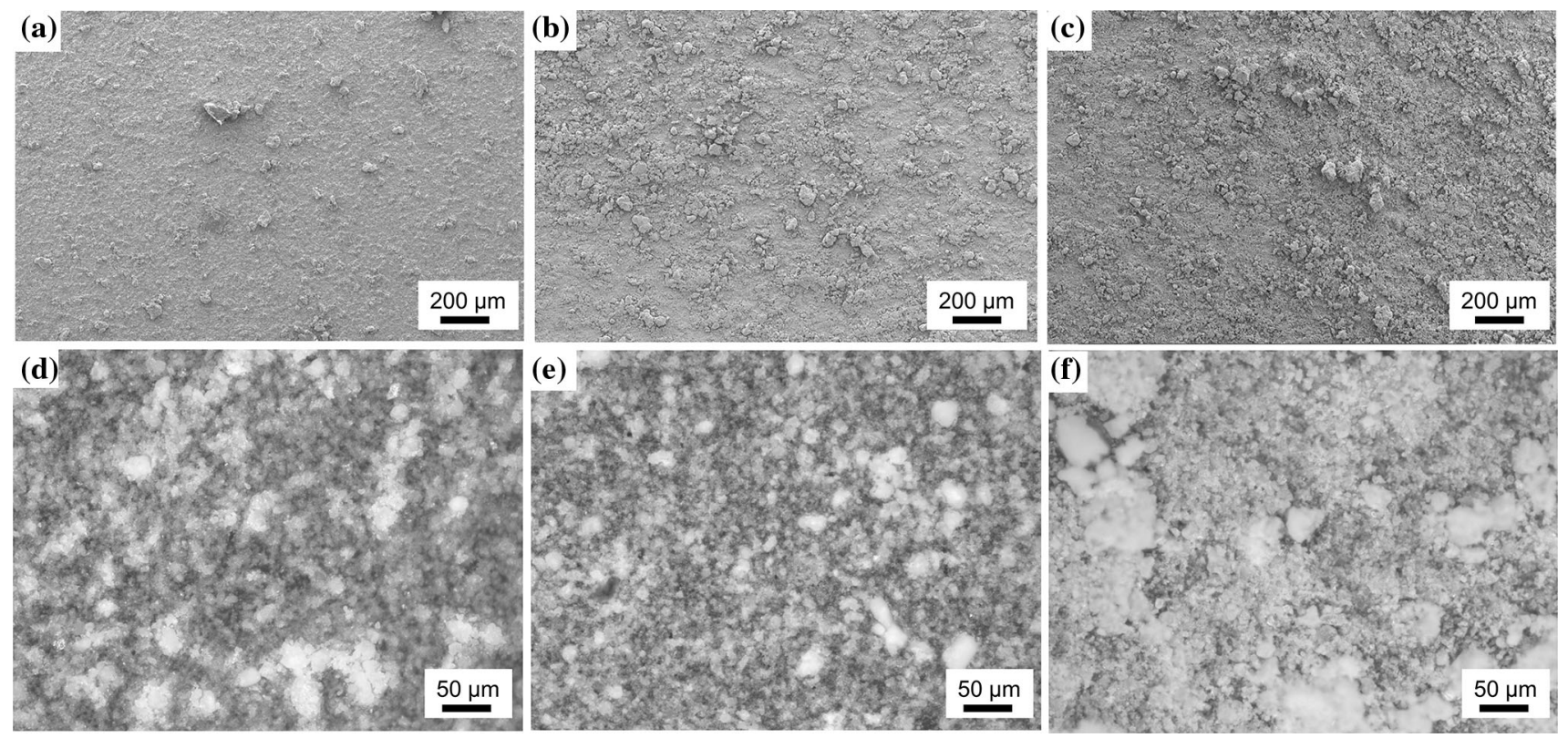

Figure 7 SEM images (top) and light microscope images (bottom) of sprayed films CN-1 (a) and (d), CN-2 (b) and (e) CN-3 (c) and (f) with different magnification, $2.5 \mathrm{x}$ (top) and 20x (bottom).

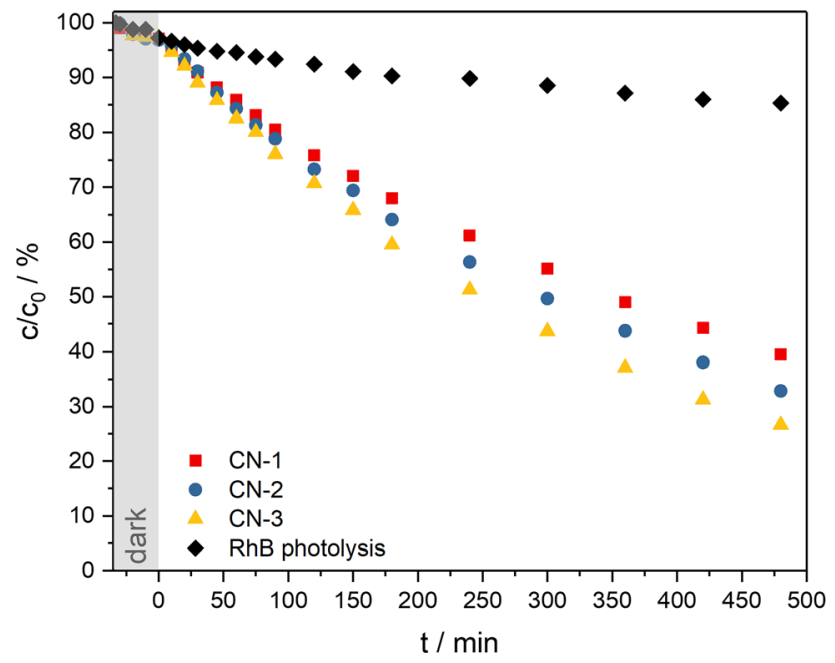

Fig. 8 Time-dependent photodegradation of an aqueous $\mathrm{RhB}$ solution $\left(1 \times 10^{-5} \mathrm{M}\right)$ under visible light irradiation with a $300 \mathrm{~W}$ Xe lamp $(t>0 \mathrm{~min})$ without catalyst and in the presence of the substrates $\mathbf{C N}-\mathbf{1}, \mathbf{C N}-2$ and $\mathbf{C N}-3$.

result in an increase in activity. Due to the highest photocatalytic activity of $\mathbf{C N}-\mathbf{1}$, analogously prepared samples were used for further investigations.

The samples were weighed after catalysis to check for leaching. The deposited mass for sample $\mathbf{C N}-\mathbf{1}$ of $0.80 \pm 0.05 \mathrm{mg}$ changes to $0.75 \pm 0.05 \mathrm{mg}$, for $\mathbf{C N - 2}$ a mass change from $1.39 \pm 0.06$ to $1.34 \pm 0.03 \mathrm{mg}$ is observed and for sample $\mathrm{CN}-3$ the mass is reduced from $2.66 \pm 0.06$ to $2.48 \pm 0.06 \mathrm{mg}$. Thus, only in case of the highest loading significant leaching is observed. In case of significant leaching, it has to be considered that dispersed $\mathrm{CN}$ particles contribute to the photocatalytic degradation and we thus conclude that the increased activity of $\mathrm{CN}-3$ is a result of leaching. In addition to weighing the samples, a scotch tape test was carried out for $\mathbf{C N}-\mathbf{1}$ (SI 15). The light microscope images before and after the test show that, in particular, larger particles were pulled off the substrate. Nonetheless, a full coverage with catalyst particles is retained.

Sample CN-1 was chosen to evaluate the time needed for an almost complete degradation of the dye RhB. While establishing the adsorption-desorption equilibrium, $6 \%$ of $\mathrm{RhB}$ was adsorbed to the surface. Within $24 \mathrm{~h} 88 \%$ of the dye was decomposed (Fig. 9a). The degradation process follows the pseudo-first-order reaction kinetics with a reaction rate constant $k$ of $3.1 \times 10^{-5} \mathrm{~s}^{-1}$ (Fig. 9b). The linearity of the plot indicates that a change in the reaction rate constant does not occur, even when the residual $\mathrm{RhB}$ concentration is reduced. Thus, the process is not diffusion limited. The UV-Vis spectra of the RhB during photocatalytic degradation are indicative for a photosensitive degradation mechanism (Fig. 9c). In addition to experiments using the Xe lamp the green $528 \mathrm{~nm} 3 \mathrm{~W}$ LED was used for irradiation of $\mathrm{CN}-1$ (Fig. 10). While irradiation of the catalyst film with 
(a)

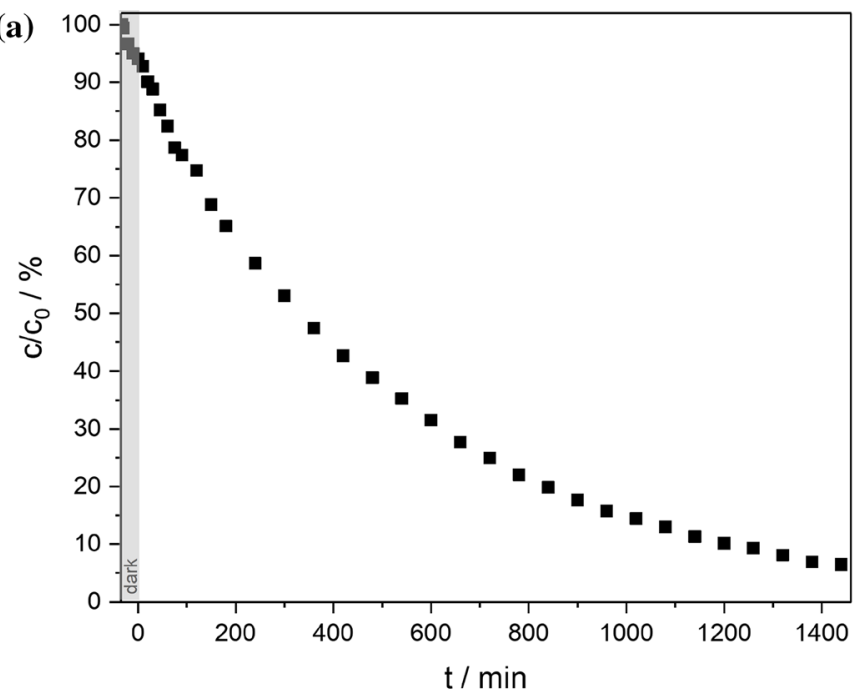

(b) 0,0

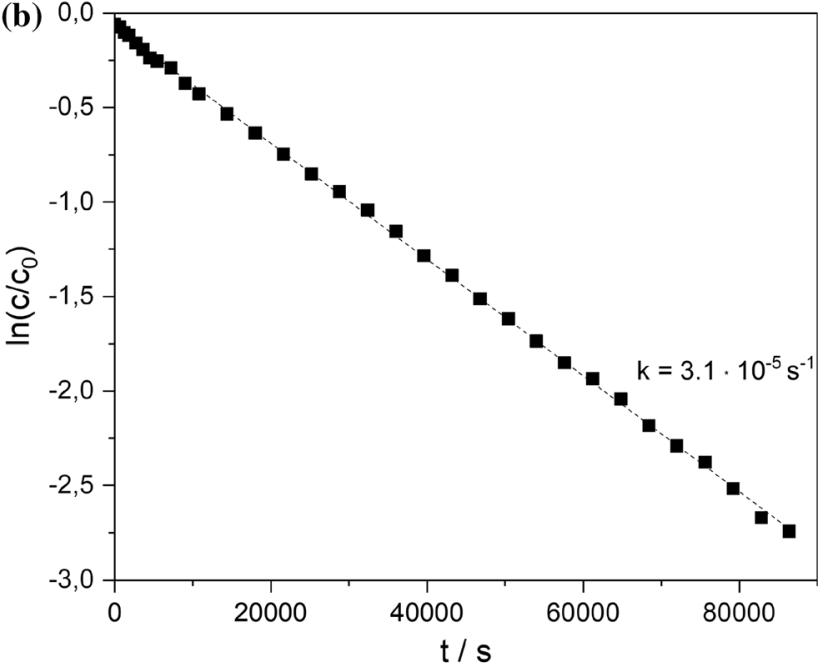

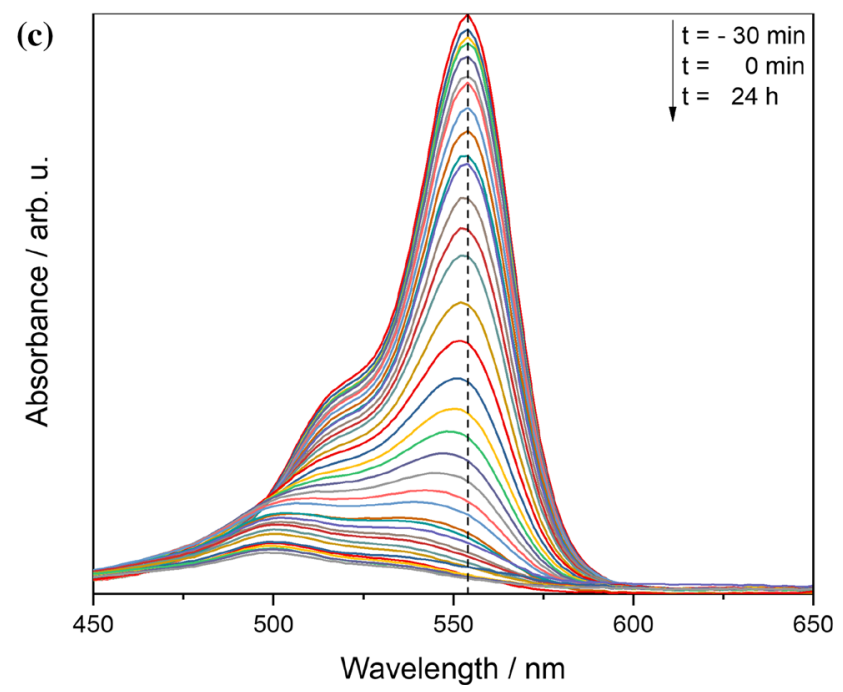

Figure 9 a Time-dependent photodegradation of an aqueous $\mathrm{RhB}$ solution $\left(1 \times 10^{-5} \mathrm{M}\right)$ under visible light irradiation with an 300 W Xe lamp $(t>0 \mathrm{~min})$ in the presence of the substrate $\mathbf{C N}-\mathbf{1}$ to evaluate the complete conversion and $\mathbf{b}$ semilogarithmic plot of

the $300 \mathrm{~W}$ Xe lamp reveals a degradation of $58 \%$ within $8 \mathrm{~h}$, as expected the $3 \mathrm{~W} 528 \mathrm{~nm}$ LED is less effective and the value drops to $25 \%$. The calculated activity of $5.2 \times 10^{-10} \mathrm{~mol} \mathrm{mg}^{-1} \mathrm{~min}^{-1}(300 \mathrm{~W} \mathrm{Xe}$ lamp) decreases to a value of $2.4 \times 10^{-10}$ mol mg ${ }^{-1} \mathrm{~min}^{-1}$ ( $3 \mathrm{~W} 528 \mathrm{~nm}$ LED). The energy efficiencies for the Xe lamp are calculated with $0.01 \mathrm{~mL} \mathrm{~W}^{-1} \mathrm{~h}^{-1}$, and it is thus many times lower than the energy efficiency of the green $3 \mathrm{~W}$ LED with $0.37 \mathrm{~mL} \mathrm{~W}^{-1} \mathrm{~h}^{-1}$.

To evaluate the potential for the photocatalytic degradation of other pollutant classes, $\mathbf{C N}-\mathbf{1}$ was used to study the degradation behavior of triclosan and EE2 using the $300 \mathrm{~W}$ Xe lamp. A concentration of the photodegradation of an aqueous $\mathrm{RhB}$ solution in the presence of the substrate $\mathbf{C N}-\mathbf{1}$ ( $\mathrm{t}>0 \mathrm{~min}$ ) $\mathrm{c}$ visible light spectra of $\mathrm{RhB}$ during the photodegradation process.

the aqueous pollutant solutions of $4 \times 10^{-5} \mathrm{M}$ was chosen, and the photolysis measurement of the respective aqueous solutions showed only minor degradation rates (Fig. 11). Using the catalyst films, $47 \%$ triclosan and $63 \%$ ethinyl estradiol were degraded after $8 \mathrm{~h}$ irradiation time. Both pollutants show absorbance in the UV region. By use of a $300 \mathrm{~W}$ Xe lamp with a 420-nm cutoff filter, only a direct excitation of the catalyst material is possible and photosensitive degradation mechanisms are suppressed. This shows that the used $\mathbf{C N}_{550}-\mathbf{C} 4$ particles enable photosensitive degradation mechanism as well as direct degradation mechanisms to a sufficient value. 


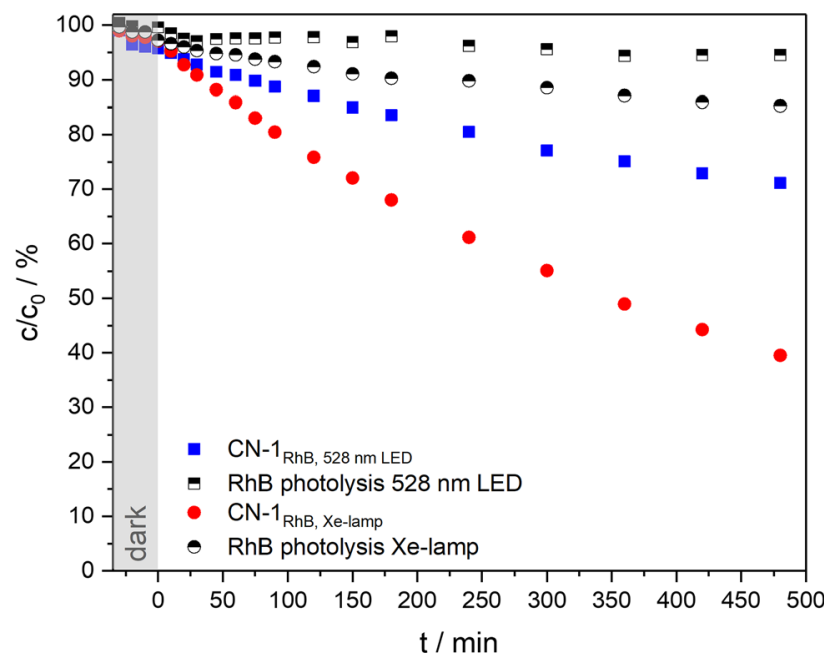

Figure 10 Time-dependent photodegradation of an aqueous $\mathrm{RhB}$ solution $\left(1 \times 10^{-5} \mathrm{M}\right)$ under visible light irradiation $(t>0 \mathrm{~min})$ without catalyst and in the presence of the substrates $\mathbf{C N}-1$ irradiated with a $300 \mathrm{~W}$ Xe lamp and a $3 \mathrm{~W} 528 \mathrm{~nm}$ LED.

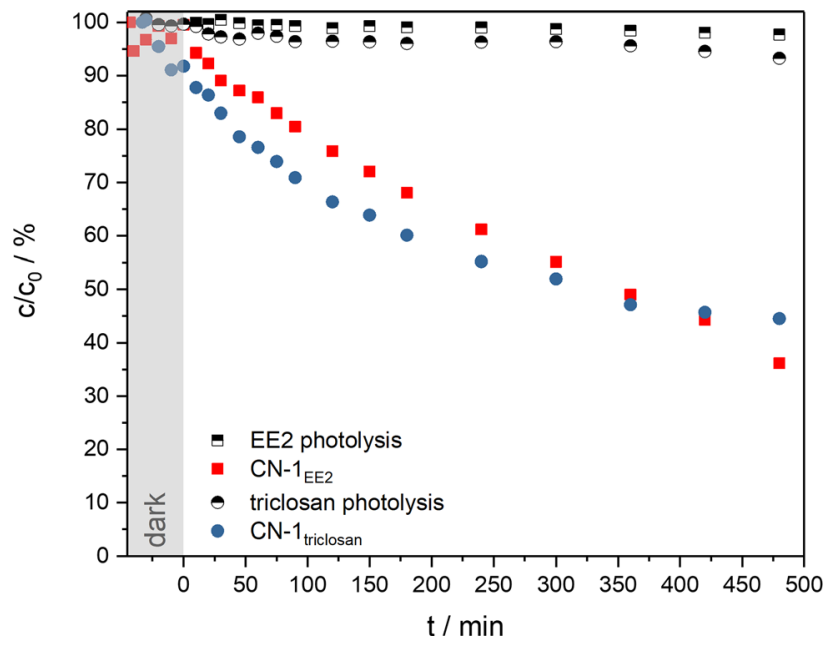

Figure 11 Time-dependent photodegradation of aqueous ethinyl estradiol and triclosan solutions $\left(4 \times 10^{-5} \mathrm{M}\right)$ under visible light irradiation with an $300 \mathrm{~W}$ Xe $\operatorname{lamp}(t>0 \mathrm{~min})$ without catalyst and in the presence of $\mathbf{C N - 1}$ as photocatalytic film.

\section{Conclusion}

Melon-like polymeric carbon nitrides materials (CN) are obtained by decomposition of dicyandiamide in ambient atmosphere, under argon and in sealed ampoules at different reaction temperatures and using different reaction times. The partial condensation and the presence of amino groups in all synthesized heptazine-based compounds was confirmed. The thermal decomposition of dicyandiamide in a molten salt provides a highly ordered triazine-based carbon nitride network $\left(\mathbf{C N}-\mathbf{M}, \mathrm{PTI} / \mathrm{Li}^{+} \mathrm{Cl}^{-}\right)$in accordance with literature data. The surface polarity and the degree of condensation of differently synthesized $\mathrm{CN}$ materials were determined by the hydrogen bonding donor ability (HBD). It is shown that the HBD has a greater influence on the photocatalytic activity of $\mathrm{CN}$ materials than the BET surface area. Triazine-based $\mathrm{CN}$ materials show a lower $\mathrm{RhB}$ degradation (10\% RhB degradation in $150 \mathrm{~min}$ ) than heptazine-based $\mathrm{CN}$ materials $(85 \% \mathrm{RhB}$ degradation in $25 \mathrm{~min}$ ). Furthermore, the gas atmosphere during the synthesis of melon like $\mathrm{CN}$ materials influences the HBD and therefore the photocatalytic activity significantly due to a higher amount of polar groups that form on the $\mathrm{CN}$ surface. The incomplete condensation of the products leads to the termination of the surface with polar groups, and these "defects" contribute significantly to the photocatalytic reactivity. Therefore, it is concluded that defect rich $\mathrm{CN}$ materials, obtained following a simple synthesis protocol using a crucible under air $(\mathrm{CN}-\mathrm{C})$, are particularly active catalysts for photocatalytic decomposition of pollutants. Predictions from the literature that the surface polarity or surface termination of $\mathrm{CN}$ materials has a significant influence on the photocatalytic activity were confirmed by providing numerical values via the determination of HBD values. The polar groups on the catalyst surface influence the adsorption behavior of the dye, which is particularly important during the observed photosensitive degradation mechanisms, and contribute to the photocatalytic activity.

The photocatalytic degradation of $\mathrm{RhB}$ with the $\mathrm{CN}$ materials under irradiation with a $300 \mathrm{~W}$ Xe lamp results from photooxidation as a result of direct excitation of the catalyst material combined with a photosensitive degradation mechanism. This assumption is supported by experiments using $3 \mathrm{~W}$ LEDs upon varying the emission wavelengths. The excitation of the RhB molecule by the use of a $528 \mathrm{~nm}$ LED was demonstrated to be very efficient, and gives high degradation rates.

It was shown that the use of energy-saving LEDs is a viable alternative to Xe lamps, as efficiencies up to 40 times higher were determined for the $3 \mathrm{~W}$ LEDs compared to the $300 \mathrm{~W}$ Xe lamp. However, the use of LED arrays with a combination of different wavelengths is suggested.

In order to evaluate the potential of immobilized photocatalysts, the $\mathbf{C N}_{550}-\mathbf{C 4}$ particles were 
deposited on a silicone tape via a spray coating technique. Small amounts of deposited CN $\left(0.14 \mathrm{mg} \mathrm{cm}^{-2}\right)$ are sufficient for an almost complete degradation of $\mathrm{RhB}$ within $24 \mathrm{~h}$. Leaching was not detected after photocatalytic experiments using substrates with low loadings ( $\mathbf{C N}-\mathbf{1})$. Furthermore, the degradation experiments for triclosan and EE2 showed promising degradation rates of up to $63 \%$ of the initial concentration. This confirms the broad application range of carbon nitride materials, even in form of coatings. We conclude that films composed of carbon nitride materials and coatings show potential for wastewater treatment plants as an additional cleaning step using sunlight to reduce the concentration of disinfectants, contraceptives and dyes in water.

\section{Experimental section}

\section{Chemicals}

Dicyandiamide (99\% Co. Alfa Aesar) was dried with $\mathrm{P}_{2} \mathrm{O}_{5}$ for 5 days under vacuum before use. The silicone tape was received from tesa SE. $\mathrm{LiCl}$ and $\mathrm{KCl}$ were received from Carl Roth.

\section{Catalyst preparation}

Dicyandiamide $(1 \mathrm{~g}, 0.01 \mathrm{~mol})$ was heated with $5 \mathrm{~K} \mathrm{~min}^{-1}$ to $550{ }^{\circ} \mathrm{C}$ for $4 \mathrm{~h}\left(\mathrm{CN}_{550}-\mathrm{C} 4\right)$, respectively, $12 \mathrm{~h}\left(\mathbf{C N}_{550}-\mathbf{C 1 2}\right)$ in a crucible under ambient atmosphere. Samples prepared under analogous conditions at $600{ }^{\circ} \mathrm{C}$ are referred as $\mathbf{C N}_{600}-\mathbf{C 4}$ and $\mathbf{C N}_{600^{-}}$ C12. The obtained yellow powder is grounded in a mortar and sieved to a particle size smaller than $100 \mu \mathrm{m}$. A sample obtained at $550{ }^{\circ} \mathrm{C}$ for $4 \mathrm{~h}$ starting from dicyandiamide in a furnace, prepared analogously to $\mathrm{CN}_{550}-\mathrm{C} 4$ but under argon atmosphere is referred to $\mathrm{CN}_{550}-\mathrm{C} 4 / \mathrm{Ar}$. To obtain $\mathrm{CN}$ particles by decomposition of dicyandiamide in a sealed ampoule, $250 \mathrm{mg}$ was placed in a $15-\mathrm{cm}$ quartz glass ampoule (length $16 \mathrm{~cm}$, diameter $1.7 \mathrm{~cm}$ and wall thickness $0.3 \mathrm{~mm}$ ) and sealed under vacuum. The ampoule is placed in a stainless steel reactor (see SI16) and heated with $5 \mathrm{~K} \mathrm{~min}^{-1}$ to $550{ }^{\circ} \mathrm{C}$ with a counterpressure of 12 bar, which was adjusted by adding water into the reactor. The temperature was set for $4 \mathrm{~h}\left(\mathrm{CN}_{550}-\mathbf{A} 4\right)$, respectively, $12 \mathrm{~h}\left(\mathrm{CN}_{550^{-}}\right.$ A12) at $550{ }^{\circ} \mathrm{C}$. Samples prepared under analogous conditions at $600{ }^{\circ} \mathrm{C}$ are referred to $\mathbf{C N}_{600}-\mathbf{A} 4$ and $\mathbf{C N}_{600}-\mathbf{A 1 2}$. To synthesize carbon nitride materials in a salt melt as flux medium $(\mathbf{C N}-\mathbf{M}), 0.2 \mathrm{~g}$ dicyandiamide, $0.9 \mathrm{~g} \mathrm{LiCl}$ and $1.01 \mathrm{~g} \mathrm{KCl}$ were mixed in a quartz glass ampoule (length $16 \mathrm{~cm}$, diameter $1.7 \mathrm{~cm}$ and wall thickness $0.3 \mathrm{~mm}$ ). The mixture is placed in a tubular furnace and heated for $6 \mathrm{~h}$ at $400{ }^{\circ} \mathrm{C}$ under argon atmosphere $\left(2 \mathrm{~L} \mathrm{~h}^{-1}\right)$ with a heating rate of $5 \mathrm{~K} \mathrm{~min}^{-1}$ starting at ambient temperature. The ampoule is than cooled down to room temperature, sealed under vacuum, placed in a stainless steel reactor in a furnace and heated to $600{ }^{\circ} \mathrm{C}$ for $12 \mathrm{~h}$ with a heating rate of $1 \mathrm{~K} \cdot \mathrm{min}^{-1}$. After cooling to room temperature, the brown solid was washed with deionized water several times to remove the flux medium. Note that during the decomposition of dicyandiamide in sealed ampoules, a high amount of ammonia gas is released; therefore, the quartz glass ampoules are under pressure (up to 12 bar) and must be opened with appropriate caution. For further details and safety instruction, see SI 16.

\section{Spray coating}

Spray coating is carried out with a HVLP (HighVolume Low-Pressure) airbrush spray gun. The spray gun is equipped with a $0.5-\mathrm{mm}$ nozzle and operates at a working pressure of 100 psi with a working distance of approximately $20 \mathrm{~cm}$. During the coating process the substrate is placed on a heat plate with a temperature of $80^{\circ} \mathrm{C}$. The as-prepared particles were dispersed in methanol with a mass concentration of $3 \mathrm{~g} \mathrm{~L}^{-1}$ and sprayed on $23 \mathrm{~mm} \times$ $25 \mathrm{~mm}$ silicone tapes attached to glass substrates of the same size. The applied masses were determined by weighing the samples after the coating process (triple determination). The scotch tape test was carried out with tape number 550 .

\section{Evaluation of photocatalytic activity}

The photocatalytic activity of the as-prepared composite coatings was evaluated in a water-cooled glass reactor $\left(T=15^{\circ} \mathrm{C}\right)$ using the coated carrier material and $35 \mathrm{~mL}$ of an aqueous solution of $1 \times 10^{-5} \mathrm{M} \mathrm{RhB}$. The reactor is equipped with a $300 \mathrm{~W}$ xenon lamp (type Cermax ${ }^{\circledR}$ VQTM ME300BF, Co. PerkinElmer, intensity of $\sim 1839 \mathrm{~W} \mathrm{~m}^{-2}$ (for other light sources see SI 12). A hot mirror filter $(\lambda \leq 700 \mathrm{~nm})$ is located within a distance of $12.3 \mathrm{~cm}$ at one side of the reactor 
and directly illuminates an area of $4.5 \mathrm{~cm}^{2}$. A cutoff filter $(\lambda \mathrm{c}(\tau i=0.50)=420 \pm 6 \mathrm{~nm}, \mathrm{GG} 420$, Co. Schott $)$ is used to remove the UV light. Before illumination, the solutions are stirred for a minimum of $30 \mathrm{~min}$ in the dark to establish the adsorption-desorption equilibrium of the dye at the catalyst surface. The progress of photodegradation and the adjustment of the adsorption-desorption equilibrium is studied by in situ UV-Vis spectroscopy. The illumination process is interrupted by stopping to stir and darkening the light beam by a cover prior to the UV-Vis measurement. The interval of measurement is timed every $10 \mathrm{~min}$ for the first $30 \mathrm{~min}$, every $15 \mathrm{~min}$ between 30 and $90 \mathrm{~min}$, every $30 \mathrm{~min}$ between 90 and $180 \mathrm{~min}$ and every $60 \mathrm{~min}$ to the last measurement at $t=480 \mathrm{~min}$. The concentration of the pollutant is determined by calculating the area under the UV-Vis curve from 450 to $600 \mathrm{~nm}$. The photodegradation is plotted as a function of the irradiation time. The $3 \mathrm{~W}$ LED lights were received from Co. Starlight. The photocatalytic activity is calculated according to Eq. (1).

$A=\frac{c_{0} \cdot V \cdot \mathrm{X}_{\mathrm{PC}}}{m_{\mathrm{cat}} \cdot t_{\mathrm{PC}} \cdot 100}$

Here, $c_{0}$ is the initial concentration of the pollutant solution, $V$ is the volume of the solution, $X_{\mathrm{PC}}$ is the conversion in moles at the time $t_{\mathrm{PC}}$ and $m_{\mathrm{Cat}}$ is the catalyst mass. The determination of the photocatalytic activity for coatings is carried out by means of the conversion after $480 \mathrm{~min}$ irradiation time. The photocatalytic activity for dispersed particles is calculated using the determined degradation after 20 min irradiation time. The determination of the energy efficiency is based on Eq. (2) in accordance with the literature [54]:

$E_{\mathrm{eff}}=\frac{X_{\mathrm{PC}} \cdot V}{P \cdot t_{\mathrm{PC}}}$

$X_{\mathrm{PC}}$ is the conversion after a defined period of time $t_{\mathrm{PC}}$, here $25 \mathrm{~min}$ for the dispersion measurements or $480 \mathrm{~min}$ for the coatings. $V$ describes the volume of the pollutant solution and $P$ the power of the light source.

\section{Materials characterization}

Powder X-ray diffraction (XRD) was carried out with a STOE STADI-P diffractometer equipped with a Ge(111)monochromator. The $\mathrm{X}$-ray source was $\mathrm{CuK}_{\alpha 1}$-radiation
$(40 \mathrm{kV}, 40 \mathrm{~mA})$. Diffuse reflectance UV-Vis spectroscopy was performed using a Carry $60 \mathrm{UV}-\mathrm{Vis}$ (Co. Agilent Technologies) equipped with a Barrelino ${ }^{\mathrm{TM}}$ (Co. Harrick Scientific Products) remote diffuse reflection probe. The band gap $E_{g}$ of the semiconductor was estimated according to the equation $(\alpha h v)^{1 / n}=A \cdot(h v-E g)$ ) where $\alpha$ is the absorption coefficient of the material, $h v$ is the photon energy and $A$ represents a proportionality constant. For a direct band gap $n=0.5$, for determination of an indirect band gap $n=2$.[55] In accordance with literature data [22] direct band gaps were assumed for all materials. The photocatalytic dye decomposition was analyzed by in situ UV-Vis spectroscopy using a Carry 60 UV-Vis spectrometer (Co. Agilent Technologies) equipped with fiber optics. ATIR spectroscopy was carried out using a Nicolet iS5 (Co. Thermo Scientific). Nitrogen physisorption isotherms were obtained at $-196{ }^{\circ} \mathrm{C}$ using an Autosorb IQ2 apparatus (Co. Quantachrome). All samples were activated in vacuum at $150{ }^{\circ} \mathrm{C}$ for $3 \mathrm{~h}$ prior to the measurements. Specific surface areas were calculated applying the single-point BET equation $(p /$ $p_{0}=0.150 \pm 0.002$ ). The light microscope images were recorded using an Axio Scope. A1 (Co. Zeiss), equipped with a HBO 100 illuminator and halogen lamp Hal 100 under polarized light. Elemental analysis (CHN analyses) were performed with a FlashEA 1112 analyzer (Co. Thermo). Solid-state NMR spectra were collected at $9.4 \mathrm{~T}$ on an Avance 400 spectrometer (Co. Bruker) equipped with double-tuned probes capable of magic angle spinning (MAS). ${ }^{13} \mathrm{C}\left\{{ }^{1} \mathrm{H}\right\}-\mathrm{CP}-\mathrm{MAS}-\mathrm{NMR}$ spectra were measured at $100.6 \mathrm{MHz}$ in 3.2 or $4.0 \mathrm{~mm}$ standard zirconium oxide rotors (BRUKER) spinning at $20 \mathrm{kHz}$ or $12 \mathrm{kHz}$, respectively. Cross-polarization $(\mathrm{CP})$ with a contact time of $3 \mathrm{~ms}$ was used to enhance sensitivity. The recycle delay was $5 \mathrm{~s}$. The spectra were referenced externally to $\mathrm{Si}\left(\mathrm{CH}_{3}\right)_{4} \quad(\delta=0.00 \mathrm{ppm})$ as well as to adamantine $\left(\delta=38.48\right.$ ppm for $\left.{ }^{13} \mathrm{C}\right)$ as secondary standard. To estimate the $\mathrm{HBD}$ ( $\alpha$-value), $0.3 \mathrm{mg}_{\left[\mathrm{Fe}(\text { phen })_{2}(\mathrm{CN})_{2}\right] /} 1 \mathrm{~g}_{\text {catalyst }}$ $0.6 \mathrm{mg}_{\left[\mathrm{Fe}(\text { phen })_{2}(\mathrm{CN})_{2}\right] /} 1 \mathrm{~g}_{\text {catalyst }}$ and $1.2 \mathrm{mg}_{\left[\mathrm{Fe}(\text { phen })_{2}(\mathrm{CN})_{2}\right] /}$ $1 \mathrm{~g}_{\text {catalyst }}$ were adsorbed onto the $\mathrm{CN}_{550}-\mathbf{C} 4$ catalyst surface. Due to a slight shift at higher dye concentrations, the concentration of $0.3 \mathrm{mg}_{\left[\mathrm{Fe}(\text { phen })_{2}(\mathrm{CN})_{2}\right] /} 1 \mathrm{~g}_{\text {catalyst }}$ was used for the other samples to allow comparability. The $\alpha$ value was calculated by means of Eq. (1). The dye solution is prepared in dried dichloromethane.

$\alpha=-7.49+0.46 \cdot \max \left(\left[\mathrm{Fe}(\text { phen })_{3}(\mathrm{CN})_{2}\right]\right)\left[10^{-3} \mathrm{~cm}^{-1}\right]$ 


\section{Acknowledgements}

We are grateful to the Europäische Sozialfonds (ESF) for financial support (Project Number 100327 773). We also thank Prof. Dr. Marc Armbrüster for access to the light microscope and Nicolas Köwitsch for sealing the ampoules and measuring SEM images, Prof. Dr. Heinrich Lang and Ute Stöß for elemental analysis, Prof. Dr. Michael Sommer and Dr. Andreas Seifert for solid-state NMR spectroscopy and Prof. Dr. Ulrich Theodor Schwarz and Matthias Wachs for emission spectra measurements. We also thank Prof. Dr. Stefan Spange and Dr. Katja Schreiter for providing the $\left[\mathrm{Fe}(\text { phen })_{2}(\mathrm{CN})_{2}\right]$, Benjamin Hentschel for BET measurements, Dr. Susann Ebert and Nicole Behme for sputtering the $\mathrm{CN}$ films.

\section{Funding}

Open Access funding enabled and organized by Projekt DEAL.

\section{Declarations}

Conflict of interest The authors declare no conflict of interest.

Supplementary Information: The online version contains supplementary material available at http s://doi.org/10.1007/s10853-021-06405-z.

Open Access This article is licensed under a Creative Commons Attribution 4.0 International License, which permits use, sharing, adaptation, distribution and reproduction in any medium or format, as long as you give appropriate credit to the original author(s) and the source, provide a link to the Creative Commons licence, and indicate if changes were made. The images or other third party material in this article are included in the article's Creative Commons licence, unless indicated otherwise in a credit line to the material. If material is not included in the article's Creative Commons licence and your intended use is not permitted by statutory regulation or exceeds the permitted use, you will need to obtain permission directly from the copyright holder. To view a copy of this licence, visit http://creativecommons.org/licen ses/by $/ 4.0 /$.
Supplementary Information: The online version contains supplementary material available at http s://doi.org/10.1007/s10853-021-06405-z.

\section{References}

[1] Van Boeckel TP, Gandra S, Ashok A, Caudron Q, Grenfell BT, Levin SA, Laxminarayan R (2014) Global antibiotic consumption 2000 to 2010: an analysis of national pharmaceutical sales data. Lancet Infec Dis 14:742-750. https://d oi.org/10.1016/s1473-3099(14)70780-7

[2] Fick J, Söderström H, Lindberg RH, Phan C, Mats Tysklind DG, Larsson J (2009) Contamination of surface, ground, and drinking water from pharmaceutical production. Environ Toxicol Chem 28:2522-2527. https://doi.org/10.1897/09-07 3.S1

[3] Hoffmann F, Kloas W (2012) Estrogens can disrupt amphibian mating behavior. PLoS One 7:e32097. https://doi. org/10.1371/journal.pone.0032097

[4] Weatherly LM, Gosse JA (2017) Triclosan exposure, transformation, and human health effects. J Toxicol Environ Health B Crit Rev 20(8):447-469. https://doi.org/10.1080/ 10937404.2017.1399306

[5] Stamatis N, Antonopoulou M, Hela D, Konstantinou I (2014) Photocatalytic degradation kinetics and mechanisms of antibacterial triclosan in aqueous $\mathrm{TiO}_{2}$ suspensions under simulated solar irradiation. J Chem Technol Biotechnol 89:1145-1154. https://doi.org/10.1002/jctb.4387

[6] Madima N, Mishra SB, Inamuddin I, Mishra AK (2020) Carbon-based nanomaterials for remediation of organic and inorganic pollutants from wastewater. A review. Environ Chem Lett 18:1169-1191. https://doi.org/10.1007/s10311-0 20-01001-0

[7] Malato S, Blanco J, Vidal A, Alarcón D, Maldonado MI, Cáceres J, Gernjak W (2003) Applied studies in solar photocatalytic detoxification: an overview. Sol Energy 75:329-336. https://doi.org/10.1016/j.solener.2003.07.017

[8.] Ameta A, Ameta SC (2017) Wastewater Treatment. In: Photocatalysis principles and applications 1 edn. CRC Press Boca Raton pp 201-217.

[9] Sobczynski A, Dobosz A (2001) Water purification by photocatalysis on semiconductors. Pol J Environ Stud 10:195-205.

[10] Hernández-Gordillo A, Bizarro M, Gadhi TA, Martínez A, Tagliaferro A, Rodil SE (2019) Good practices for reporting the photocatalytic evaluation of a visible-light active semiconductor: $\mathrm{Bi}_{2} \mathrm{O}_{3}$, a case study. Catal Sci Technol 9:1476-1496. https://doi.org/10.1039/c9cy00038k 
[11] Gaya UI, Abdullah AH (2008) Heterogeneous photocatalytic degradation of organic contaminants over titanium dioxide: a review of fundamentals, progress and problems. J Photochem Photobiol C 9(1):1-12. https://doi.org/10.1016/j.jph otochemrev.2007.12.003

[12.] Wankhade AVG, G. S.; Dhonde, MG, Khaty, NT, Thakare SR (2013) Removal of organic pollutant from water by heterogenous photocatalysis: a review. Res J Chem Environ 17:84-94.

[13] $\mathrm{Fu} \mathrm{J}$, Yu J, Jiang C, Cheng B (2018) g- $\mathrm{C}_{3} \mathrm{~N}_{4}$-based heterostructured photocatalysts. Adv Energy Mater 8:1701503. https://doi.org/10.1002/aenm.201701503

[14] Qi K, Liu S-y, Zada A (2020) Graphitic carbon nitride, a polymer photocatalyst. J Taiwan Inst Chem Eng 109:111-123. https://doi.org/10.1016/j.jtice.2020.02.012

[15] Li Y, Li X, Zhang H, Xiang Q (2020) Porous graphitic carbon nitride for solar photocatalytic applications. Nanoscale Horiz 5:765-786. https://doi.org/10.1039/d0nh00046a

[16] Zou H, Yan X, Ren J et al (2015) Photocatalytic activity enhancement of modified $\mathrm{g}-\mathrm{C}_{3} \mathrm{~N}_{4}$ by ionothermal copolymerization. J Materiom 1:340-347. https://doi.org/10.1016/j. jmat.2015.10.004

[17] Markushyna Y, Smith CA, Savateev A (2019) Organic photocatalysis: carbon nitride semiconductors versus molecular catalysts. Eur J Org Chem 1294-1309. https://doi. org/10.1002/ejoc.201901112

[18] Schwinghammer K, Tuffy B, Mesch MB et al (2013) Triazine-based carbon nitrides for visible-light-driven hydrogen evolution. Angew Chem Int Ed 52:2435-2439. https://doi. org/10.1002/anie.201206817

[19] Lau VW-H, Yu VW-Z, Ehrat F et al (2017) Urea-modified carbon nitrides: enhancing photocatalytic hydrogen evolution by rational defect engineering. Adv Energy Mater 7:1602251. https://doi.org/10.1002/aenm.201602251

[20] Li X, Yu J, Jaroniec M (2016) Hierarchical photocatalysts. Chem Soc Rev 45:2603-2636. https://doi.org/10.1039/c5c s00838g

[21] Cheng N, Tian J, Liu Q et al (2013) Au-nanoparticle-loaded graphitic carbon nitride nanosheets: green photocatalytic synthesis and application toward the degradation of organic pollutants. ACS Appl Mater Interfaces 5:6815-6819. http s://oi.org/10.1021/am401802r

[22] Algara-Siller G, Severin N, Chong SY et al (2014) Triazinebased graphitic carbon nitride: a two-dimensional semiconductor. Angew Chem 53:7450-7455. https://doi.org/10.100 2/anie. 201402191

[23] Schwarzer A, Saplinova T, Kroke E (2013) Tri-s-triazines (sheptazines)-From a "mystery molecule" to industrially relevant carbon nitride materials. Coord Chem Rev 257:2032-2062. https://doi.org/10.1016/j.ccr.2012.12.006
[24] Rahman MZ, Davey K, Qiao S-Z (2018) Carbon, nitrogen and phosphorus containing metal-free photocatalysts for hydrogen production: progress and challenges. J Mater Chem A 6:1305-1322. https://doi.org/10.1039/c7ta10404a

[25] Fina F, Callear SK, Carins GM, Irvine JTS (2015) Structural investigation of graphitic carbon nitride via XRD and neutron diffraction. Chem Mater 27:2612-2618. https://doi.org/ 10.1021/acs.chemmater.5b00411

[26] Lotsch BV, Doblinger M, Sehnert J, Seyfarth L, Senker J, Oeckler O, Schnick W (2007) Unmasking melon by a complementary approach employing electron diffraction, solid-state NMR spectroscopy, and theoretical calculationsstructural characterization of a carbon nitride polymer. Chem Eur J 13:4969-4980. https://doi.org/10.1002/chem. 200601759

[27] Niu P, Zhang L, Liu G, Cheng H-M (2012) Graphene-like carbon nitride nanosheets for improved photocatalytic activities. Adv Func Mater 22:4763-4770. https://doi.org/10. 1002/adfm.201200922

[28] Kroke E (2014) gt- $\mathrm{C}_{3} \mathrm{~N}_{4^{-}}$das erste stabile binäre Kohlenstoff(IV)-nitrid. Angew Chem 126:11314-11316. https://doi. org/10.1002/ange.201406427

[29] Lotsch BV, Schnick W (2006) From triazines to heptazines: novel nonmetal tricyanomelamiinates as precursors for graphitic carbon nitride materials. Chem Mater 18:1891-1900. https://doi.org/10.1021/cm052342fCCC:\$33.50

[30] Schwinghammer K, Mesch MB, Duppel V, Ziegler C, Senker J, Lotsch BV (2014) Crystalline carbon nitride nanosheets for improved visible-light hydrogen evolution. J Am Chem Soc 136:1730-1733. https://doi.org/10.1021/ja 411321s

[31] Bojdys MJ, Müller J-O, Antonietti M, Thomas A (2008) Ionothermal synthesis of crystalline, condensed. Graphitic Carbon Nitride Chem Eur J 14:8177-8182. https://doi.org/ 10.1002/chem. 200800190

[32] Fettkenhauer C, Weber J, Antonietti M, Dontsova D (2014) Novel carbon nitride composites with improved visible light absorption synthesized in $\mathrm{ZnCl}_{2}$-based salt melts. RSC Adv 4:40803-40811. https://doi.org/10.1039/c4ra08236b

[33] Bai X, Wang L, Wang Y, Yao W, Zhu Y (2014) Enhanced oxidation ability of $\mathrm{g}-\mathrm{C}_{3} \mathrm{~N}_{4}$ photocatalyst via $\mathrm{C} 60$ modification. Appl Catal B 152-153:262-270. https://doi.org/10. 1016/j.apcatb.2014.01.046

[34] Tyborski T, Merschjann C, Orthmann S, Yang F, Lux-Steiner MC, Schedel-Niedrig T (2013) Crystal structure of polymeric carbon nitride and the determination of its processtemperature-induced modifications. J Phys Condens Matter 25:395402. https://doi.org/10.1088/0953-8984/25/39/ 395402 
[35] Hasija V, Raizada P, Sudhaik A et al (2019) Recent advances in noble metal free doped graphitic carbon nitride based nanohybrids for photocatalysis of organic contaminants in water: a review. Appl Mater Today 15:494-524. https://doi. org/10.1016/j.apmt.2019.04.003

[36] Wirnhier E, Döblinger M, Gunzelmann D, Senker J, Lotsch BV, Schnick W (2011) Poly(triazine imide) with intercalation of lithium and chloride ions $\left[\left(\mathrm{C}_{3} \mathrm{~N}_{3}\right)_{2}\left(\mathrm{NH}_{\mathrm{x}} \mathrm{Li}_{1-} \mathrm{x}\right)_{3}\right.$ - $\mathrm{LiCl}]$ : a crystalline $2 \mathrm{D}$ carbon nitride network. Chem Eur J 17:3213-3221. https://doi.org/10.1002/chem.201002462

[37] Wang Y, Wang X, Antonietti M (2012) Polymeric graphitic carbon nitride as a heterogeneous organocatalyst: from photochemistry to multipurpose catalysis to sustainable chemistry. Angew Chem Int Ed 51(1):68-69. https://doi.org/ 10.1002/anie. 201101182

[38] Seifert S, Seifert A, Brunklaus G, Hofmann K, Rüffer T, Lang H, Spange S (2012) Probing the surface polarity of inorganic oxides using merocyanine-type dyes derived from barbituric acid. New J Chem 36:674-684. https://doi.org/10. 1039/c2nj20835k

[39] Ding D, Hou Q, Su Y et al (2019) $\mathrm{g}-\mathrm{C}_{3} \mathrm{~N}_{4} / \mathrm{TiO}_{2}$ hybrid film on the metal surface, a cheap and efficient sunlight active photoelectrochemical anticorrosion coating. J Mater Sci Mater Electron 30:12710-12717. https://doi.org/10.1007/s1 0854-019-01635-z

[40] Zhou M, Hou Z, Chen X (2018) The effects of hydrogenation on graphitic $\mathrm{C}_{3} \mathrm{~N}_{4}$ nanosheets for enhanced photocatalytic activity. Part Part Syst Charact 35:1700038. https://doi. org/10.1002/ppsc.201700038

[41] Kumar S, Karthikeyan S, Lee A (2018) $\mathrm{g}_{-} \mathrm{C}_{3} \mathrm{~N}_{4}$-based nanomaterials for visible light-driven photocatalysis. Catalysts 8:74. https://doi.org/10.3390/catal8020074

[42] Zhu J, Xiao P, Li H, Carabineiro SA (2014) Graphitic carbon nitride: synthesis, properties, and applications in catalysis. ACS Appl Mater Interfaces 6:16449-16465. https://doi.org/ 10.1021/am502925j

[43] Schlesinger M, Weber M, Schulze S, Hietschold M, Mehring $\mathrm{M}$ (2013) Metastable beta- $\mathrm{Bi}_{2} \mathrm{O}_{3}$ nanoparticles with potential for photocatalytic water purification using visible light irradiation. ChemOpen 2:146-155. https://doi.org/10.1002/ope n.201300013

[44] Hofmann M, Rößner L, Armbrüster M, Mehring M (2020) Thin coatings of $\alpha$ - and $\beta-\mathrm{Bi}_{2} \mathrm{O}_{3}$ by ultrasonic spray coating of a molecular bismuth oxido cluster and their application for photocatalytic water purification under visible light. ChemOpen 9:277-284. https://doi.org/10.1002/open.201900323

[45] Horvath-Bordon E, Riedel R, McMillan PF et al (2007) High-pressure synthesis of crystalline carbon nitride imide,
$\mathrm{C}_{2} \mathrm{~N}_{2}(\mathrm{NH})$. Angew Chem 119:1498-1502. https://doi.org/1 0.1002 /ange. 200603851

[46] Wang K, Li Q, Liu B, Cheng B, Ho W, Yu J (2015) Sulfurdoped $\mathrm{g}_{-} \mathrm{C}_{3} \mathrm{~N}_{4}$ with enhanced photocatalytic $\mathrm{CO}_{2}$-reduction performance. Appl Catal B 176-177:44-52. https://doi.org/ 10.1016/j.apcatb.2015.03.045

[47] Wang J, Huang J, Xie H, Qu A (2014) Synthesis of g- $\mathrm{C}_{3} \mathrm{~N}_{4} /$ $\mathrm{TiO}_{2}$ with enhanced photocatalytic activity for $\mathrm{H}_{2}$ evolution by a simple method. Int J Hydrogen Energy 39:6354-6363. https://doi.org/10.1016/j.ijhydene.2014.02.020

[48] Wang W, Kou X, Zhao R, Su Y (2021) Molten salt derived crystalline graphitic carbon nitride to enable selective photooxidation of benzyl alcohol. J Nanopart Res 23:88. https://d oi.org/10.1007/s11051-021-05168-7

[49] Fang S, Lv K, Li Q, Ye H, Du D, Li M (2015) Effect of acid on the photocatalytic degradation of rhodamine $\mathrm{B}$ over g- $\mathrm{C}_{3} \mathrm{~N}_{4}$. Appl Surf Sci 358:336-342. https://doi.org/10.101 6/j.apsusc.2015.07.179

[50] Liu N, Li T, Zhao Z et al (2020) From triazine to heptazine: origin of graphitic carbon nitride as a photocatalyst. ACS Omega 5(21):12557-12567. https://doi.org/10.1021/acsome ga.0c01607

[51] Gao H, Yan S, Wang J, Huang YA, Wang P, Li Z, Zou Z (2013) Towards efficient solar hydrogen production by intercalated carbon nitride photocatalyst. Phys Chem Chem Phys 15:18077-18084. https://doi.org/10.1039/c3cp53774a

[52] Wang Q, Chen C, Zhao D, Ma W, Zhao J (2008) Change of adsorption modes of dyes on fluorinated $\mathrm{TiO}_{2}$ and its effect on photocatalytic degradation of dyes under visible irradiation. Langmuir 24:7338-7345. https://doi.org/10.1021/la80 0313sCCC: $\$ 40.75$

[53] Watanabe T, Takizawa T, Honda K (1977) Photocatalysis through excitation of adsorbates 1. Highly efficient $\mathrm{N}$-deethylation of rhodamine $\mathrm{B}$ adsorbed to cadmium sulfide. J Phys Chem 81:1845-1851. https://doi.org/10.1021/ j100534a012

[54] Fernandes RA, Sampaio MJ, Faria JL, Silva CG (2020) Aqueous solution photocatalytic synthesis of p-anisaldehyde by using graphite-like carbon nitride photocatalysts obtained via the hard-templating route. RSC Adv 10:19431-19442. h ttps://doi.org/10.1039/d0ra02746d

[55] Tauc J, Grigorovici R, Vanou A (1966) Optical properties and electronic structure of amorphous germanium. Phys Stat Sol 15:627-637. https://doi.org/10.1002/pssb.19660150224

Publisher's Note Springer Nature remains neutral with regard to jurisdictional claims in published maps and institutional affiliations. 